\title{
Land Use and General Equilibrium Implications of a Forest-Based Carbon Sequestration Policy in the U.S.
}

\begin{abstract}
A comparative static Computable General Equilibrium model was used to assess the impacts of forestbased carbon payments on sequestration, land use, and agricultural commodity prices in the U.S. A modified 2008 regional Social Accounting Matrix, considering land as a heterogeneous factor, was used as the model's main input. The matrix was projected to its 2050 counterpart using capital and labor growth projections. The forest-generated carbon offset sources considered were afforested set-asides, commercial forestry intensification and harvested wood products. A new dataset on regional afforestation carbon uptake rates and costs was used to include afforested set-asides as latent activities. For a carbon offset price of $\$ 20 / \mathrm{MT} \mathrm{CO}_{2}, 12 \%$ of U.S. annual emissions could be sequestered in 2050. More than half of the additional carbon sequestered (611 million MT $\mathrm{CO}_{2}$ ), compared to the 2050 baseline, would be attributed to set-asides and composed mainly of softwood forests. High carbon prices would increase land prices resulting in the diversion of $15 \%$ and $8 \%$ of pasture and cropland to carbon set-asides, respectively, mainly in the Central Plains. The high agricultural land diversion would force activities to intensify production systems driving the prices of beef up by $14 \%$ as well as oilseeds and grains by $3 \%$ and $4 \%$, respectively.
\end{abstract}

Keywords: Carbon sequestration, afforestation, set-aside, land-use change, computable general equilibrium, heterogeneous land, major land resource areas, management intensity. 


\section{Introduction and Motivation}

Among the options to mitigate the risk of global climate change, two are of great importance: 1) carbon source reduction programs and 2) carbon sink enhancement programs. If the country implemented a domestic greenhouse gas $(\mathrm{GHG})$ reduction program, the first option would require a great deal of investment in the development of new technologies, which translates into time and capital [1]. According to Stavins and Richards [2], paying no serious attention to the second alternative would lead to "incorrect and overly pessimistic conclusions about the cost and feasibility of addressing global climate change."

The United States accounted for approximately a quarter of global GHG emissions (6.8 billion metric tons) in 2010. Nevertheless, land use, land-use change, and forestry (LULUCF) acted as net sinks reducing total GHG emissions, by approximately 1 billion metric tons (MT), to a net total of 5.8 billion MT in 2010 [3]. Hence, the role of the agriculture and forestry sectors as net carbon sinks has made policy makers aware of the great potential of these sectors to contribute to the national and global effort to manage atmospheric GHGs. Evidence of this is the inclusion of the changes in carbon stocks attributed to LULUCF as eligible domestic offset practices in the most recent and ambitious attempt to address climate change in the country - House Resolution (H.R.) 2454 in the 111th Congress. ${ }^{1}$

The cost of different sequestration approaches is critical information for policymakers as they consider various GHG mitigation options. Among the most promising sequestration alternatives to date, forestbased carbon sequestration has proven to be a relatively inexpensive means of addressing climate change [4]. Moreover, afforestation (planting trees on land previously used for other purposes) is the sequestration alternative that would potentially contribute the most towards the generation of domestic carbon offsets from LULUCF $[5,6]$. Afforestation is the alternative with the highest per-acre and total potential carbon sequestration for land used either for cropland or pastureland [5]. According to Birdsey [7], the estimated sequestration rates for forest coming from cropland and pastureland are 2.89 - 6.31 and 2.67 - 7.67 MT of $\mathrm{CO}_{2}$ equivalent per acre, respectively.

While the sequestration potential from afforestation has been widely studied and demonstrated in the literature $[1,8,9,2]$, the structure of the forest-generated carbon credit mechanism is still in question. As a solution to one of the most concerning subjects regarding the credit mechanism, permanence, policy makers have suggested forestland set-asides. Evidence of this is the body of literature assessing the economic impacts from setting aside already existing forestland as carbon graveyards by prohibiting carbon removals in exchange of carbon sequestration payments $[10,6,11,12,13] .{ }^{2}$ However, these studies conclude that forest set-asides become a feasible alternative at extremely high carbon prices due to the high opportunity cost of

\footnotetext{
${ }^{1}$ H.R. 2454, also known as the American Clean Energy and Security Act of 2009, was an energy bill that sought to reduce global warming pollution among other objectives. The bill passed in the House of Representatives on June 26, 2009. However, it did not pass in the Senate and was placed on the legislative calendar under General Orders. Calendar No. 97. The H.R. 2454, section 722 (d) (1) (A), allowed covered entities to collectively use offset credits to demonstrate compliance for up to a maximum of 2 billion tons of GHG emissions annually.

${ }^{2}$ In the literature, setting forestland aside is equivalent to extending rotation age indefinitely.
} 
not harvesting timber. Nevertheless, the literature lacks a study of the economic implications of converting agricultural land (e.g. cropland and pastureland) into forestland and setting it aside as carbon graveyards to ensure permanence - these activities will be called "afforested set-asides". Due to the lower land rents paid for cropland and pastureland in some regions of the U.S., the low opportunity costs of converting agricultural land into carbon graveyards would be reflected in lower carbon offset costs. Although setting aside afforested land would require taking agricultural land out of production; it would be economically objective to weight the benefits from a lower carbon offset price and the impacts on the commodities grown in the displaced agricultural area.

According to Sun and Sohngen [13], if the government implemented a carbon payment program for afforestation projects, including forest-based sequestration practices other than set-asides would result in a more efficient (i.e. less leakage) and less expensive sequestration program. Hence, the extent of the carbon sequestration efficiency, cost and land-use change implications would not only depend on set-asides but also on the overall management intensity adopted in commercially, private timberland as a result of the carbon payments $[14,15,16]$. These carbon-intensive forest management practices would not only impact forest carbon stocks but the annual contribution of harvested wood products (HWP) in use and in solid-waste disposal sites (SWDS) towards the GHG removals by LULUCF as well [17].

Although the GHG sequestration contributions and economic implications of carbon-intensive forest management practices have been treated extensively in previous studies, the literature lacks an economic assessment of the joint effects of afforested set-asides and forest management intensities on GHG sequestration efforts, land-use change, and HWP carbon pools. The potential generation of domestic carbon offsets from a possible government-funded afforestation program depends on hypothetical carbon offset prices, treeestablishment costs, land rents for alternative uses, competing prices of agricultural products, and carbon sequestration rates for different geographical regions and tree species. Hence, to analyse the potential contribution from afforestation, an integrated assessment framework is needed to account for all of these factors.

\subsection{Previous Afforestation Studies}

Due to the various cost estimation methods used in previous studies, there is a wide range of forestbased carbon sequestration costs estimates from $\$ 3$ to $\$ 550$ per $\mathrm{MT}$ of $\mathrm{CO}_{2}$ equivalent $[2,8]$. Three approaches predominate the literature: bottom-up engineering studies, econometric studies based on the revealed-preferences premise, and sector optimisation models. Although all three approaches treat the forest sector in detail, only the latter treat the agricultural sector in any extent. Sector optimisation models have been extensively used in the literature to represent the interactions between the agriculture and forestry sectors $[18,19,5,10,6]$ or solely to represent the forestry sector $[20,21,22,23,12]$. Among the strengths of these models is the accurate and dynamic representation of the sectors under scrutiny, which facilitates a policy-impact analysis, taking the other sectors in the economy as exogenous variables. However, these models have failed to endogenise the economy-wide impacts and feedbacks from other economic sectors, 
institutions (i.e. households and government) and factor markets (i.e. land market). These models have also failed to explicitly include the market for land as a heterogeneous factor and, as a result, have ignored the substitutability of land use among different geo-climatic areas [24]. Ignoring heterogeneous land mobility and substitution between agriculture and forestry will possibly result in erroneous estimates of marginal GHG abatement costs [15].

The development of an integrated assessment framework considering land as a heterogeneous factor using different geo-climactic areas would result in more suitable and realistic land allocations among competing uses by considering environmental and agronomic limiting factors. Most land-use economic models in the literature use national and global datasets based on the Agro-Ecological Zones (AEZs) concept [25, 26, 15]. Out of the 18 global AEZs considered by these models the United States is only covered by six. An alternative classification system offering a finer geo-climatic disaggregation of land at the sub-national level is the Major Land Resource Area (MLRA) classification developed by the U.S. Natural Resource Conservation Service (NRCS) with 296 different areas. ${ }^{3}$ The main criteria used by NRCS to categorise land into the different MLRAs are: physiographic, geological, climatic, water, soil, biological and land use characteristics. Although the development of an economic model reflecting the substitutability of heterogeneous land at the sub-national level would facilitate the impact analysis of regional phenomena, the literature lacks such models including the MLRA concept.

An approach that explicitly models the competition for heterogeneous land from the agriculture and forestry sectors and accounts for the effects on the different sectors, institutions (e.g. households and government) and factors (e.g. labor and capital) in a specific economy is the Computable General Equilibrium (CGE) modelling approach. Although CGE models have been extensively used to simulate the economywide effects of potential climate change policies [28, 29], very few have considered the effects on, and from, the forestry sector as a carbon sink $[26,15,16]$. Even fewer have considered the effect of afforestation on land-use change for different geographically associated regions in the United States [15].

Due to the complexity posed by the inclusion of the dynamic structure of forestry into CGE models, all previous studies treating forests as potential carbon sinks have resorted to a comparative static framework contrasting alternative equilibria to a derived baseline of the economy at some selected year in the future. Golub et al. [15] and Michetti and Rosa [16] used the recursive dynamic and comparative static versions of a static CGE model, respectively, relying on exogenous carbon-offset supply curves estimated with the partial equilibrium, dynamic optimisation model of global timber markets and forest carbon stocks described in Sohngen and Mendelsohn [23]. By using exogenous carbon-offset supply curves, these models fail to directly endogenise carbon sequestration by the forestry sector and, hence, its responses to changing market conditions $[30,16]$.

Following the same comparative static framework, an alternative to directly endogenise forest-based

\footnotetext{
${ }^{3} \mathrm{~A}$ complete list, description and location of each MLRA can be found in NRCS [27]. The continental U.S. contains 226 MLRAs and the rest belong to Alaska, Hawaii and other off-shore U.S. territories and possessions, such as Puerto Rico.
} 
carbon sequestration in a CGE model would be to include afforestation activities in the model producing carbon-offsets and competing for agricultural land, labor, capital and intermediate inputs. To achieve this, a special dataset is needed considering consistent and regionalised land use and rent data, GHG sequestration rates and afforestation costs.

\subsection{Objective}

The objective of the current study is to analyse the long-run impacts of a government-funded forestbased carbon sequestration program on: 1) the annual carbon removal contributions by afforested set-asides, privately-owned timberland and HWP; 2) land-use change in different MLRAs; and 3) the production and trade of competing commodities in the United States using a comparative static CGE framework. The forestgenerated carbon offset sources considered were afforested set-asides, the intensification of the commercial logging industry and harvested wood products. This study contributes to the literature by being the first one to endogenise afforested set-asides in different geo-climatic regions in the U.S. using a CGE framework and to adopt a new national dataset including regional afforestation sequestration rates and costs, and treating agricultural land as a heterogenous factor of production by including land use and rent data for different geo-climatic regions (i.e. MLRAs) in the United States. The states included in the regional aggregation considered reflect the highest concentration of privately-owned timberland in the United States.

The following sections of the paper will describe: 1) the static CGE model in a brief manner; 2) the incorporation of afforested set-asides as latent activities; 3) the representation of management intensity by the commercial logging industry; 4) the incorporation of carbon payments in the CGE model; 5) the inclusion of HWP pools; 6) the explicit modelling of heterogeneous land supply and demand; 7) the development of regional sequestration rates and afforestation costs; 8) the regional and national carbon removal contributions, land-use change and general equilibrium results; and 9) conclusions.

\section{Analytical Framework}

The model used for this study is a comparative static regional CGE model first developed in Monge [31], modified for this study and described in appendix A. For the sake of brevity, only the relevant sections of the model for this study will be described in the main document, the rest is fully described in appendix A. The model's structure is a hybrid between Lofgren et al. [32] and Bryant et al. [33] and is well-suited to analyse the economic shocks affecting land allocation between agriculture and forestry. The model is based on a modification of the Social Accounting Matrix (SAM) from the Impact Analysis for Planning (IMPLAN) dataset for 2008 as explained in Monge et al. [34]. ${ }^{4}$ As in almost all CGE models, production of goods and services are modelled as a set of "nested" production functions. That is, the output of one production

\footnotetext{
${ }^{4}$ The modifications performed to the SAM consisted on: 1) integrating detailed agricultural and forest land-use and rent data from several public sources to represent land as a heterogeneous factor of production; 2) reorganising proprietors' income, present in national economic accounts, into payments to conventional primary factors of production (labor, capital and heterogeneous land); and 3) reallocating indirect business taxes to appropriately represent sales and import taxes in the SAM.
} 
function becomes an input of one or more additional production functions. For example, on the right hand side of figure 1, an "Intermediate Composite" good is produced using various commodities ("Commodity 1, ..., Commodity $\mathrm{N}+1$ ) as inputs. This intermediate composite good, and a "Value-Added Composite" good, subsequently become inputs into the production of "Commercial Logging Output" (i.e., the output of the economy's commercial logging activity). Each individual production function is referred to as a "nest". In this model, production is represented by Constant Elasticity of Substitution (CES) technology (including Leontief and Cobb-Douglas special cases). Each nest thus has an associated substitution elasticity parameter (e.g, $\sigma_{A T}, \sigma_{A V}$, and so forth in figure 1). Transformation of factors of production or commodities into specialized forms is similarly modelled using nested Constant Elasticity of Transformation (CET) functions. For example, general agricultural land is transformed into cropland, pastureland, or afforested set-aside in an "Agricultural Land" CET nest, with associated substitution elasticity $\sigma_{L A}$.

A critical step in any CGE modelling exercise is "calibration" of production and transformation nestsspecification of the relevant functions' parameters. For each nest in this model, this entails the specification of the substitution elasticity parameter $(\sigma)$, and parameters in CES functions governing the scale of production and input productivity (and analogous parameters for CET functions). This often entails the specification of $\sigma$ based on economic reasoning, followed by determination of the values for other parameters consistent with the chosen $\sigma$ and the base-year SAM or input-output data. Alternatively, all parameters for a nest may be chosen to result in one or more derived demand functions for the nest's inputs that are consistent with external economic knowledge or evidence.

The following subsections will describe in detail the calibration of specific nests in the model that present particular challenges, such as the need to integrate standard SAM data and non-standard data sources (e.g., bio-physical data such as average $\mathrm{CO}_{2}$ production of forests in different regions), calibration of activities not reflected in the base year data, or the calibration of components to which model results are particularly sensitive. Table 1 lists the notational structure followed throughout the manuscript for consistency's sake.

Table 1: Notational Structure

\begin{tabular}{ll}
\hline Item & Notation \\
\hline Endogenous variables & Upper-case Latin letters \\
Parameters & Lower-case Latin letters \\
Set indices & subscripts \\
Nests' input quantities and prices & $Q X$ and $P X$ \\
Nests' output quantities and prices & $Q Y$ and $P Y$ \\
Substitution and transformation elasticities & $\sigma$ with nest name as subscript \\
\hline
\end{tabular}

Following previous afforestation studies using CGE models, a comparative static framework was used in this study contrasting alternative equilibria to a derived baseline of the economy in the year 2050. The comparative static approach used in this study is described in Dixon and Rimmer [35]. Such approach has been widely used in the environmental economics literature (e.g. [36, 37, 16]). This "entails inserting, in the model calibration data, scenario values for some key economic variables, to identify a hypothetical general 
equilibrium state for the future" [36]. Due to the static nature of the CGE model, the general equilibrium results obtained are considered long-run phenomena since factor mobility across activities was allowed and all the elasticities used to calibrate the model are considered long-run substitution/transformation elasticities. Same as in Bosello et al. [36], the focus was primarily on the supply side, by imposing estimates for future endowments of labor and capital. These variables are commonly exogenous in CGE models so it is sufficient to change their levels from those of the initial calibration year of the model (i.e. 2008) to those estimated in the future (i.e. 2050). As suggested by Dixon and Rimmer [35], the capital and labor accumulation were smoothed across time but introduced into the model as a single step. The 2008 SAM was projected to its 2050 counterpart by increasing labor and capital endowments using robust peer-reviewed projections. Capital was assumed to increase by $182 \%$ following the annual Gross Domestic Product growth forecast of $2.5 \%$ in Paltsev et al. [29]. The labor force was assumed to increase by $23 \%$ according to the 2050 forecast in Toossi [38]. Baseline GHG emissions were assumed to increase from 7,048 million $\mathrm{MT}$ of $\mathrm{CO}_{2}$ equivalent in 2008 to 10,800 million MT of $\mathrm{CO}_{2}$ equivalent in 2050 according to Paltsev et al. [29].

For this study, the sequestration dynamic phenomenon was accommodated into a long-run framework by using average annual carbon flows estimated from the forest ecosystem's average annual carbon increment over the cutting period. Since the objective of this study is to identify the economy-wide effects of an afforestation program at some point in the future, the adjustment path followed by the forestry sector is not important. According to Dee [39] and Sohngen et al. [30], if the objective of the study aims at long-run phenomena, a comparative static framework contrasting alternative equilibria without tracing the adjustment paths to either equilibrium can certainly be used to compare alternative forestry scenarios under constant annual timber production and sequestration rates. Hence, for the forestry sector, the baseline and each counterfactual equilibrium are simulated with different average annual carbon flows on a peracre basis as will be explained later. By adopting a long-run closure, the comparative static approach sidesteps complex short-term, dynamic effects such as the substitutability between carbon sequestration and production. According to Sohngen et al. [30], most of the short-term forest-based sequestration potential, which is relatively high, comes from changes in rotation ages. Since sequestration can only be achieved by withholding timber production, it is expected that high carbon prices would result in timber production declines. Hence, the short-term impacts of rotation age extensions in the economy have been left out in this study. However, in the long-run, area expansion and increased management intensity complement timber production. That is why both phenomena have been included in this study: increased management intensity in commercial forestry and area expansion through afforested set asides.

Following the long-run framework, two types of permanence are implied in this study: sequestration and land-use permanence. Permanent conversion of agricultural land to forest (herafter, "afforested set-asides") and the commercial logging industry fulfil the land-use permanence since the land that is afforested cannot be converted back to its previous use. Only afforested set-asides comply with the sequestration permanence since wood harvests are not allowed from them. The annual emissions from the wood products from domestic 
commercial timberland harvests were discounted from the annual sequestration contributions by the commercial logging industry as will be explained later. The carbon accounting implications of such permanence assumptions for set-asides is that there is no carbon release from them until 2050. Such implications entails that only long-rotation species ( $>42$ years) would be planted in such set-asides disregarding short-rotation species that could be harvested before 2050. Such short-rotation alternatives could prove feasible in certain regions and their inclusion would be a good extension of the approach used in this study. By considering a 42-year time horizon until 2050, this exercise also disregards the future costs of replanting such set-asides, which could prove more expensive than afforesting crop or pasture land due to the presence of logging residues. The species aggregation and economic approach adopted in this exercise preclude identifying how far in the future certain set-asides would need to be reforested.

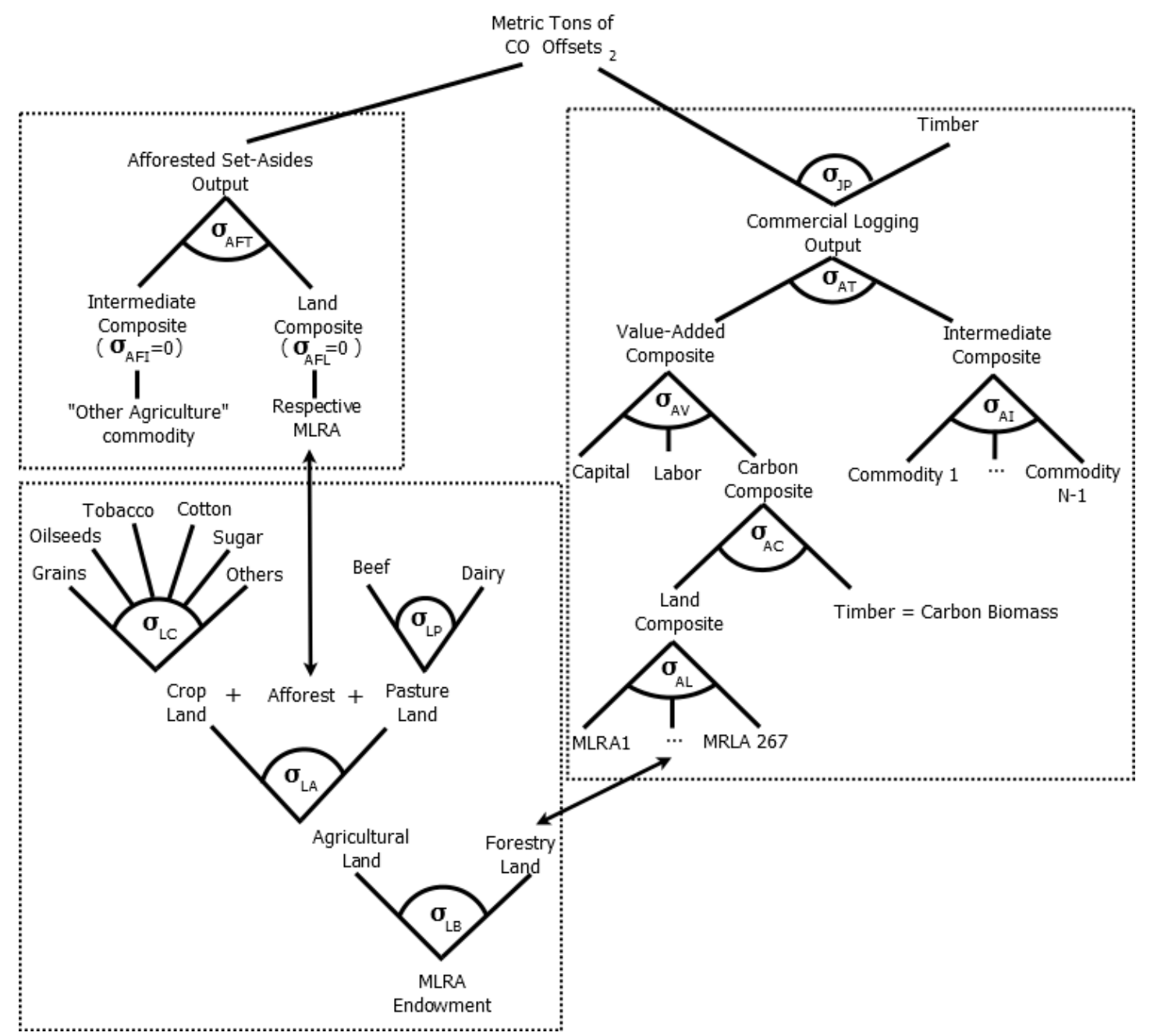

Figure 1: Representation of Forest-Based Carbon Sequestration in the CGE Model

\subsection{Permanent Conversion of Agricultural Land to Forest (Afforested Set-Asides)}

Afforested set-asides are modelled in the CGE as latent activities meaning that they are present but not active in the model's baseline since the price for $\mathrm{CO}_{2}$ offsets is zero. The latent afforested set-asides 
become active in the different counterfactual scenarios. An array of afforested set-asides was created using combinations of MLRAs, major timber categories and the previous use of the afforested land: crop or pastureland. ${ }^{5}$ The set-asides combinations are conditioned on existing softwood and hardwood forest (public and private) acreage planted in the different MLRAs.

Following a similar nesting structure as that used for activities, afforested set-asides are modelled as a set of top nests $(A F T)$ that use as inputs the output produced by a land nest $(A F L)$ and an intermediate input nest $(A F I)$ as shown in the upper left dotted square of figure $1 .{ }^{6}$ Every afforested set-aside's top nest demands land only from its respective MLRA through the land nest. Every afforested set-aside's top nest also demands only the "other agriculture" aggregate commodity since it includes afforestation services. ${ }^{7}$ Hence, it is assumed that the labor and capital requirements for afforestation are indirectly provided by the afforestation companies under contract. Zero substitution elasticities were assumed for all afforestation nests.

As depicted in the upper left dotted square of figure 1, the afforested set-asides' top nests produce $\mathrm{CO}_{2}$ offsets on a per-MT basis. Hence, the land and intermediate input nests were calibrated with quantities and prices on a per-MT basis. For the land nest, the input quantities $(Q X A F L)$ used were regional annual $\mathrm{CO}_{2}$ uptake rates $(s e q)$, as listed in equation 1, obtained from the literature in MT/acre/year and converted to acres/MT/year. The prices $(P X A F L)$ used were the per-acre rents (rent) of the incumbent land-use types as listed in equation 2 .

$$
\begin{gathered}
Q X A F L_{a f, l}=\text { seq }_{l, \text { use }, \text { wood }}, \\
P X A F L_{a f, l}=\text { rent }_{l, u s e}
\end{gathered}
$$

where af represents the afforested set-aside combinations, $l$ the MLRAs, wood the timber categories and use the incumbent land-use types. A mapping was developed from the af set to the $l$, wood and use sets to assign the different acreage figures.

For the intermediate input nest, the input quantities $(Q X A F I)$ used were annualised afforestation costs (cost) obtained from the literature in $\$$ /acre and converted to $\$ / \mathrm{MT}$ by using the regional annual $\mathrm{CO}_{2}$ uptake rates $(s e q)$ as listed in equation 3. The prices (PXAFI) assumed for the baseline were unity.

$$
Q X A F I_{a f,{ }^{\prime} \text { otherag }}=\text { cost }_{l, \text { use }, \text { wood }} * \operatorname{seq}_{l, \text { use }, \text { wood }},
$$

where 'otherag' is the other agriculture aggregate commodity. A mapping was also developed from the af set to the $l$, wood and use sets to assign the different costs.

\footnotetext{
${ }^{5}$ For example, if softwood was planted on cropland in the Southern Coastal Plain MLRA (MLRA code 234), an afforestation activity was created representing the existing combination (i.e. MLRA234, softwood, cropland).

${ }^{6}$ The reason for using nests for land and intermediate inputs in this case is to separate the baseline input quantities and prices for each nest. The $A F L$ nest uses per-acre rents and acreage as its baseline input price and quantity whereas the $A F I$ nest uses unity as its baseline input price.

${ }^{7}$ This commodity includes the IMPLAN sector of support activities for agriculture and forestry. The sector of support activities for agriculture and forestry includes companies that provide afforestation services.
} 


\subsection{Commercial Logging Industry Baseline Calibration}

For the commercial logging industry, carbon revenues are generated in the counterfactual equilibrium when the $\mathrm{CO}_{2}$-offset price is positive. The production of $\mathrm{CO}_{2}$ offsets by this industry is modelled as a byproduct of timber production as depicted in the dotted square on the right in figure 1. The joint production $(J P)$ nest of the commercial logging activity was calibrated with the logging commodity production value from the SAM and the 2008 net annual change in carbon stocks from regional private timberland of 422 million MT of $\mathrm{CO}_{2} \cdot{ }^{8}$ After calibrating the parameters with the 2008 SAM, as previously mentioned, the economic variables in the model were projected to the future resulting in a 2050 baseline annual change in carbon stocks of 507 million $\mathrm{MT}$ of $\mathrm{CO}_{2}$. This 2050 baseline carbon offset total of 507 million $\mathrm{MT}$ of $\mathrm{CO}_{2}$ would be compliant of carbon payments creating an incentive for private timberland owners to engage in carbon-intensive forest management practices.

The 2008 regional net annual change in carbon stocks was estimated using the national figure of 857 million $\mathrm{MT}$ of $\mathrm{CO}_{2}$ coming from all kinds of forestland [3]. Since this study considers only the private timberland share of total forestland in 38 states, the appropriate portion had to be estimated from the national net annual change in carbon stocks. According to the EPA [3], the mean net annual non-soil stock change (2000-2010) from the 38 states was approximately 460 million $\mathrm{MT}$ of $\mathrm{CO}_{2}$ or about $73 \%$ of the total in the nation. ${ }^{9}$ However, only $68 \%$ (or 317 million acres) of the forestland in the 38 states was private timberland [40]. Hence, the $J P$ nest was calibrated with 422 million $\mathrm{MT}$ of $\mathrm{CO}_{2}$ (or 857 million * $73 \% *$ $68 \%$ ), which would be the amount of $\mathrm{CO}_{2}$ sequestered by the commercial logging industry in the regional aggregation in the 2008 baseline. By considering that the 422 million $\mathrm{MT}$ of $\mathrm{CO}_{2}$ were sequestered on 317 million acres of private timberland, a regional sequestration rate of $1.33 \mathrm{MT}$ of $\mathrm{CO}_{2} /$ acre/year was estimated. This regional sequestration rate was compared to the inventory-based estimate of average annual total net ecosystem exchange (NEE) for forestlands in the regional aggregation of $1.34 \mathrm{MT}$ of $\mathrm{CO}_{2} /$ acre/year for the 7-year period of 2000-2006 estimated with the publicly-available dataset from Wei et al. [41] and used in Hayes et al. [42] for U.S. national estimates. Using the previously estimated annual regional sequestration rate of $1.33 \mathrm{MT}$ of $\mathrm{CO}_{2}$ /acre/year, the $2008 \mathrm{SAM}$ was projected to its 2050 counterpart resulting in a 2050 baseline annual regional sequestration rate of $1.60 \mathrm{MT}$ of $\mathrm{CO}_{2} /$ acre/year or a total of 507 million MT of $\mathrm{CO}_{2}$ sequestered.

\subsection{Management Intensity by Commercial Logging Industry}

The structure of the inputs' nests for the commercial logging industry, in contrast to the rest of the industries considered, follows the structure adopted in Hertel et al. [43] and Golub et al. [15] to model the expected carbon stock increments from positive $\mathrm{CO}_{2}$ offset prices as presented in the dotted square on the

\footnotetext{
${ }^{8}$ In contrast to afforested set-asides, regional sequestration rates were not necessary for the commercial logging industry.

${ }^{9}$ Although mean net annual non-soil stock change does not include the entire net annual carbon stock change in the forest ecosystem, it is highly representative accounting for approximately $78 \%$. Hence, the $73 \%$ estimated from the mean net annual non-soil stock change from the 38 states is a good representation of the net annual carbon stock change in the forest ecosystem of the regional aggregation.
} 
right in figure 1. By including a carbon composite nest $(A C)$, involving land and the own-use of the logging commodity, carbon stocks can be augmented by increasing either timberland acreage or biomass in existing forests. The own-use of the logging commodity can be considered a representation of the volume of forest biomass on a given area [15]. By setting the substitution elasticity of the $A C$ nest to zero $\left(\sigma_{A C}=0\right)$, land and biomass would be used at the same proportion as in the baseline representing an average management intensity regardless of the $\mathrm{CO}_{2}$ offset price.

Nevertheless, by calibrating the $A C$ nest with a positive substitution elasticity $\left(\sigma_{A C}>0\right)$ the model would be allowing the substitution of land for biomass. Hence, a biomass-intensive management regime would be simulated by sequestering $\mathrm{CO}_{2}$ at a higher annual rate in contrast to the 2050 baseline $(>1.60$ $\mathrm{MT}$ of $\mathrm{CO}_{2} /$ acre/year). The intensive management regime was simulated by calibrating the $A C$ nest with a substitution elasticity that would result in sequestration increments (due to management) similar to a widely accepted study - Murray et al. [6] - at similar carbon prices. The forecasted 50-year sequestration increment in Murray et al. [6] using FASOMGHG due to forest management intensity at a price of $\$ 15 / \mathrm{MT} \mathrm{CO}_{2}$ was

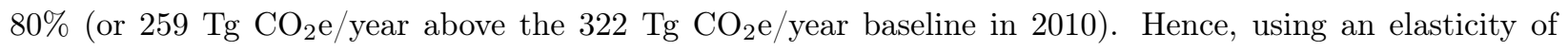
0.6 would simulate a similar sequestration increment due to management intensity at a price of $\$ 15 / \mathrm{MT}$ $\mathrm{CO}_{2}$ from 2008 to 2050 in this study. Such relative sequestration increments are also in line with the ones estimated by Foley et al. [14] on purely physical (not economic) grounds. ${ }^{10}$

\subsection{Land Markets}

As previously mentioned, the explicit (1) treatment of land as a heterogeneous factor of production, and (2) representation of a market for land, makes CGEs a good alternative to partial equilibrium models when considering the economy-wide impacts form environmental policies [24]. Explicitly including land as a heterogeneous factor through different MLRAs and modelling the ease with which land may be shifted between alternatives, through the CET functions and its respective supply elasticities, potentially results in more accurate estimates of marginal GHG abatement costs [15]. The explicit representation of a land market allows modelling factor payments to landowners (i.e. households and enterprises) and their subsequent change in consumption and saving patterns, which in turn will affect production and land-use patterns as well. All of these endogenous relationships included in any generic CGE model are either ignored (usual case) or exogenously specified in a partial equilibrium model.

Similar to Bryant et al. [33], land markets have been modelled following Hertel et al. [44] where land supply is divided into different geo-climatic regions to reflect land heterogeneity. In this study, land endowments have been divided into the 166 MLRAs included in the regional aggregation considered. From these endowments, land is supplied to three broad land uses (crop, pasture and forestry) and from these to all the different agricultural activities. To reflect rent and transformability differences among the alternative uses, land supply has been divided into three nesting levels as depicted in the lower left dotted square of figure 1: 1) a

${ }^{10}$ Note the increments in Table 4 of Foley et al. [14] under the Voluntary Carbon Standard for Southern pine species. 
nest that supplies land from every MLRA $(l)$ to forestry and agricultural land; 2) a nest within agriculture (QXLA) that supplies land to crop- and pasture-related activities; and 3) two nests, one within cropland $(Q Y L C)$ and one within pastureland $(Q Y L P)$, that supply land to all the agricultural activities. To model competition for land from the afforested set-asides activities (af), the agricultural land supplied to cropland and pastureland is also demanded by the set-asides $(Q X A F L)$ as formulated in equations 4 and 5 and depicted in the middle nest of the lower left dotted square of figure 1.

$$
\begin{aligned}
& Q X L A_{l,,^{\prime} r l d^{\prime}} \geq Q Y L C_{l}+\sum_{a f} Q X A F L_{a f, l}, \\
& Q X L A_{l,,^{\prime} p s l d^{\prime}} \geq Q Y L P_{l}+\sum_{a f} Q X A F L_{a f, l} .
\end{aligned}
$$

The CETs used for the first two nests $(L B$ and $L A$ ), were estimated from own-return elasticities by following the procedure used by Hertel et al. [44] and Villoria et al. [45] and developed by Ahmed et al. [46]. The own-return elasticities were developed by Lubowski [47] considering: (1) responses to markets, and (2) secular transitions of land use over time. The latter could be considered an inertia factor, which is independent of changes in profitability. ${ }^{11}$ The resulting CETs were -0.02 and -1.96 for the $L B$ and $L A$ nests, respectively. The LB CET obtained from the procedure developed by Ahmed et al. [46] was too high (-2.02) due to the high transformability between crop and pastureland. Hence, the LB CET used (-0.02) was the one adjusted with the own-return elasticity of forestland, which was considered low enough to represent the low transformability between forestland and agricultural land. ${ }^{12}$ The CETs for $L C$ and $L P$ were set at -3 to reflect a higher transformability.

Although the CETs represent some form of inertia, there are other factors that are not included such as managerial flexibility, product price volatility, and non-market benefits. Approaches in the literature such as real options, stochastic analysis and non-market valuation could prove that short-term agricultural production cycles, lower output price volatility and higher non-market benefits maybe more appealing to a land-owner that does not solely rely on the net present value criterion.

To calibrate the parameters for the different land nests, Monge and Bryant [48] estimated the acreage and land rent payments for cropland, pastureland and timberland for every county in the continental U.S. using national and public databases sponsored by the U.S. Department of Agriculture (USDA). These land-use endowments and rent payments were aggregated and matched with the agricultural activities competing for land and for each MLRA following Monge et al. [34]. For this study we employ actual per-acre rents and acreage as the baseline land prices and quantities, respectively. Cropland and pastureland acreage and rents

\footnotetext{
${ }^{11}$ All own-return elasticities were obtained from Ahmed et al. [46]. A 50-year horizon was assumed for the own-return elasticity for forestland (0.02), cropland (0.27) and pastureland (0.44). The own-return elasticity for agricultural land (0.35) was estimated as the average between cropland and pastureland.

${ }^{12}$ Some MLRAs resulted in negligible land movements from forestland to the set-asides. Since we do not consider reforested set-asides in this study, the $L B$ CETs of these MLRAs were set to zero without affecting the results. The elasticities of some MLRAs were also set lower due to the small rent payments coming from the commercial logging industry.
} 
where obtained from the National Agricultural Statistics Service (NASS) [49]. Pastureland demands from the dairy and beef industries were estimated using the Animal Unit (AU) concept developed by the Natural Resource Conservation Service (NRCS) [50] and the livestock inventory figures from the National Agricultural Statistics Service (NASS) [49]. ${ }^{13}$ Private timberland acreage was obtained from the Forest Service (FS) [40] and the rents were estimated by annualising the Net Present Value (NPV) figures developed by Sohngen [51]. ${ }^{14}$

The state-level aggregation on which this study is based includes states with a high share of timberland owned by the private sector - the Eastern half of the U.S. including North and South Dakota, Nebraska, Colorado, Oklahoma and Texas. ${ }^{15}$ In accordance to the premise that land-use change in a market economy is the reflection of the landowner's effort to maximise land rents, this study only considers privately-owned timberland. The response of the commercial logging industry to market-based incentives by increasing management intensity is more plausible under a private regime rather than a public one. Although public forests (reserved or unproductive) would play an important role in the generation of carbon offsets, they require public legislative mandates that are fundamentally different than the market-based approaches addressed in this study. ${ }^{16}$

\subsection{Carbon Market}

The aggregate supply of $\mathrm{CO}_{2}$ offsets by the different afforested set-asides $(Q Y A F T)$ and the commercial logging industry $(Q X J P)$, at their respective prices $(P Y A F T$ and $P X J P)$, is entirely demanded by the government through a budget allocation $(C B)$ as formulated in equation $6 .{ }^{17}$

$$
\begin{aligned}
C B= & \left(\sum_{a f} Q Y A F T_{a f} * P Y A F T_{a f}\right) \\
& +\left(Q X J P_{a l g, c r b} * P X J P_{a l g, c r b}\right),
\end{aligned}
$$

where alg represents the commercial logging industry and $c r b$ represents the $\mathrm{CO}_{2}$ offsets produced as a by-product.

Although the model estimates market-clearing prices in the form of shadow values from a set of excess supply functions, the $\mathrm{CO}_{2}$-offset market-clearing prices ( $p c r b$ ) were exogenously set as parameters and altered to obtain $\mathrm{CO}_{2}$-offset supply curves. The excess supply specification for $\mathrm{CO}_{2}$ offsets is presented as equation

\footnotetext{
${ }^{13} \mathrm{The} \mathrm{AU}$ is "a convenient denominator for use in calculating relative grazing impact of different kinds and classes of domestic livestock and of common wildlife species" [50]. Hence, by multiplying the number of cattle heads in the inventories by the AU, an approximate estimate of the pastureland demanded by the livestock sectors was obtained.

${ }^{14}$ Sohngen [51] estimated timberland NPV figures for 13 different timber types in the U.S. assuming an infinite series of rotations and constant timber prices. These were annualised into land rents using a discount rate of $5 \%$.

${ }^{15}$ Although Colorado, Texas and South Dakota do not present a high concentration of private timberland, they were included due to the high presence of pastureland in some of their MLRAs.

${ }^{16} \mathrm{As}$ will be explained later, the contribution from public forests to national sequestration efforts as carbon sinks has been left at the 2008 baseline level. The same applies to privately-owned timberland in the states that have been left out of the regional aggregation.

${ }^{17}$ Following the mixed complementarity structure of the PATH solver used in GAMS, equation 6 was paired with the $\mathrm{CO}_{2}$ offset demand variable $(Q C D)$.
} 
7 where the quantities supplied, coming from afforested set-asides and commercial logging, must be greater than or equal to quantities demanded $(Q C D){ }^{18}$

$$
\sum_{a f} Q Y A F T_{a f}+Q X J P_{a l g, c r b}-Q C D \geq 0
$$

To force the model to generate positive $\mathrm{CO}_{2}$ offsets, every afforested set-aside is required to supply a minimum amount of $\mathrm{CO}_{2}$ offsets $(\mathrm{min})$ as shown in equation $8 .{ }^{19}$ When this inequality is binding, a $\mathrm{CO}_{2}$-offset premium is generated as a shadow value $(P R) .{ }^{20}$

$$
Q Y A F T_{a f} \geq \min _{a f}
$$

As formulated in equation 9, the price paid to each afforestation activity ( $P Y A F T)$ is equal to the parametric $\mathrm{CO}_{2}$-offset price ( $\left.p c r b\right)$ plus a premium $(P R)$ paid only if the activity is supplying the required minimum. If the set-aside is supplying more than the minimum requirement, it is paid only the $\mathrm{CO}_{2}$-offset price. $^{21}$

$$
P Y A F T_{a f}=p c r b+P R_{a f}
$$

The $\mathrm{CO}_{2}$-offset price paid to the commercial logging industry $(P X J P)$ is equal to the parametric $\mathrm{CO}_{2}$ offset price $(p c r b)$ as formulated in equation $10 .^{22}$

$$
P X J P_{a l g, c r b}=p c r b \text {. }
$$

The model is structured such that if $\mathrm{CO}_{2}$-offset supply and demand are equal in equation 7, the government budget $(C B)$ is positive and the supply quantities are simultaneously determined in equations 6 and 7 given that the $\mathrm{CO}_{2}$-offset price ( $\left.p c r b\right)$ is exogenously set.

\subsection{Harvested Wood Products}

To measure the impacts of a carbon-intensive management regime by the commercial logging industry on GHG emissions and sequestration contributions from HWP; a relationship was established between annual domestic wood harvest and the annual change in HWP carbon stocks. By using the annual figures developed by the EPA [3] using the methods described in Skog [17]; a linear relationship was estimated between the annual HWP carbon stock changes $(\triangle H W P)$ and annual domestic wood harvest $(H R V)$ as formulated in equation 11 with an $\mathrm{R}^{2}$ of 0.80 .

$$
\triangle H W P=-72.43+(0.38 * H R V)
$$

Following the previous relationship, the annual HWP carbon stock change was estimated for every coun-

\footnotetext{
${ }^{18}$ Equation 7 was paired with the government budget variable $(C B)$.

${ }^{19}$ This minimum offset generation parameter was set to a very low value $\left(1 \times 10^{-6}\right)$.

${ }^{20}$ Equation 8 was paired with the premium $(P R)$.

${ }^{21}$ Equation 9 was paired with $P Y A F T$.

${ }^{22}$ Equation 10 was paired with $P X J P$.
} 
terfactual equilibrium. The annual domestic wood harvest from different equilibria was estimated by using the timber production percent change $(\% \triangle Q X J P)$, in any counterfactual equilibrium, and the baseline 2050 harvested wood figure (hrvbs) as formulated in equation 12. According to the EPA [3], the total wood harvest in 2008 was 398 million $\mathrm{MT}$ of $\mathrm{CO}_{2}$ equivalent. Considering the 2050 baseline projection, the total wood harvest in 2050 resulted in 557 million $\mathrm{MT}$ of $\mathrm{CO}_{2}$ equivalent.

$$
H R V=h r v b s *\left(1+\% \triangle Q X J P_{a l g, t m b}\right) .
$$

To estimate the carbon stock change of HWP in use and in SWDS in any counterfactual equilibrium, the same shares from 2008 were applied as formulated in equations 13 and 14 . Approximately $23 \%$ of the 82 million $\mathrm{MT}$ of $\mathrm{CO}_{2}$ recorded as the change in HWP stocks were in use (\%inuse) in 2008, the other $77 \%$ were in SWDS (\%swds).

$$
\begin{aligned}
& \triangle I N U S E=\triangle H W P * \% \text { inuse } \\
& \triangle S W D S=\triangle H W P * \% \text { swds } .
\end{aligned}
$$

According to Skog [17], the annual GHG emissions $(G H G)$ from products made from domestic wood harvest (including fuelwood) can be estimated by subtracting the annual wood harvest figure from the annual HWP carbon stock change as formulated in equation 15.

$$
G H G=\triangle H W P-H R V .
$$

These annual GHG emissions figure were subtracted from the annual GHG removal contributions by the commercial logging industry since, in contrast to the set-asides, the carbon stocks can be harvested and permanence cannot be ensured. According to Skog [17], the annual HWP carbon stock change is a function of decay rates for different HWP among other things. All the complex intermediate steps detailed in Skog [17] to arrive at equation 15 have been sidestepped by identifying the statistically significant linear relationship presented in equation 11.

\section{Regional Sequestration and Establishment Cost Data for Afforested Set-Asides}

In contrast to the overall annual $\mathrm{CO}_{2}$ uptake rate estimated for the commercial logging industry, the carbon uptake rates and afforestation costs for the afforested set-asides were obtained for different regions, wood categories and land-use types in the U.S. This section will briefly describe the sources of data used to obtain robust regionalised figures. For a more detailed discussion refer to appendices B and C.

The regional annual changes in carbon storage data from converting cropland and pastureland to forest were obtained from Birdsey [7] and are listed in table B.1. These estimates consider several forest ecosystem components: trees, soil, forest floor, and understory vegetation. The original forest stock changes estimated by Birdsey [7], their conversion into $\mathrm{CO}_{2}$ equivalent and the procedure to distribute the regional uptake rates into the different MLRAs included in the regional aggregation are included in appendix $\mathrm{B}$. The regional 
annual $\mathrm{CO}_{2}$ uptake rates were used in equations 1 and 3 for the afforested set-aside latent activities.

The most cited studies reporting regional afforestation costs for cropland and pastureland are Moulton and Richards [52] and Bair and Alig [53]. Both studies were used to estimate a complete set of afforestation costs for every region in Moulton and Richards [52] and every major timber category in Bair and Alig [53]. Since the estimates in Bair and Alig [53] are in 2002 dollars, to adjust for inflation, a factor of 1.04 was estimated by considering the percent change between the Producers Price Index (PPI) in 2002 to 2008. Following previous literature, treatment costs were annualised to spread the cost burden throughout the life of the plantation [52]. This carbon accounting approach is known in the literature as the levelization method and it consists on annualising (levelling) the present value of the treatment costs over the period of carbon flows and dividing it by the annual carbon capture rate [2]. Hence, the annualised (levelled) costs are shown in the last four columns of table C.2. To be consistent with the interest rate used in Monge and Bryant [48] to estimate timberland rents, an interest rate of $5 \%$ was considered to obtain different capitalisation factors for different regions and major timber categories, depending on the period of carbon flows. The periods and capitalisation factors are also shown in table C.2. For a detailed explanation of the cost estimation and distribution among the different MLRAs refer to appendix C. The regional afforestation costs were used in equation 3 for the afforested set-aside latent activities.

To switch from agricultural to forestland, it was assumed in this study that the rents paid for the incumbent land-use type, in the baseline, would have to be paid to set aside land for carbon sequestration. Hence, the cropland and pastureland per-acre rent figures (rent) estimated in Monge and Bryant [48] and described in section 2.4 were used in equation 2 for the afforested set-aside latent activities. The procedure to include the land rents in the model is explained in detail in appendix D.

\section{Results}

Having modelled afforested set-asides and a carbon-intensive management regime by the commercial logging industry, different counterfactual equilibria were generated by altering the exogenous $\mathrm{CO}_{2}$-offset price from $\$ 1$ to $\$ 20 / \mathrm{MT} \mathrm{CO}_{2}$ in 2050 as shown in figure 2 . First, as previously mentioned, the 2008 baseline was projected to its 2050 counterpart by considering the growth of labor and capital endowments in one step. Hence, the 2050 baseline and counterfactual equilibria contain long-run general equilibrium adjustments for a 42-year time horizon. Following the comparative static framework used in the literature, these counterfactual equilibria were contrasted to the 2050 baseline with a zero carbon-offset price.

As shown in figure 2, when considering the 2008 and 2050 projected total GHG emissions, net forest and HWP removals decrease as a percentage of total emissions from $9 \%$ in 2008 to approximately $6 \%$ in 2050 if there is no carbon-offset price. To maintain the same level of removals as a percent of total emissions in 2050 compared to 2008, it would be necessary to adopt a carbon-intensive management regime and to pay a carbon-offset price of $\$ 12 / \mathrm{MT} \mathrm{CO}_{2}$ to afforested set-asides and the commercial logging industry. A carbon offset price of $\$ 20 / \mathrm{MT} \mathrm{CO}_{2}$ results in a $12 \%$ of total emissions being removed by forests and HWP. 


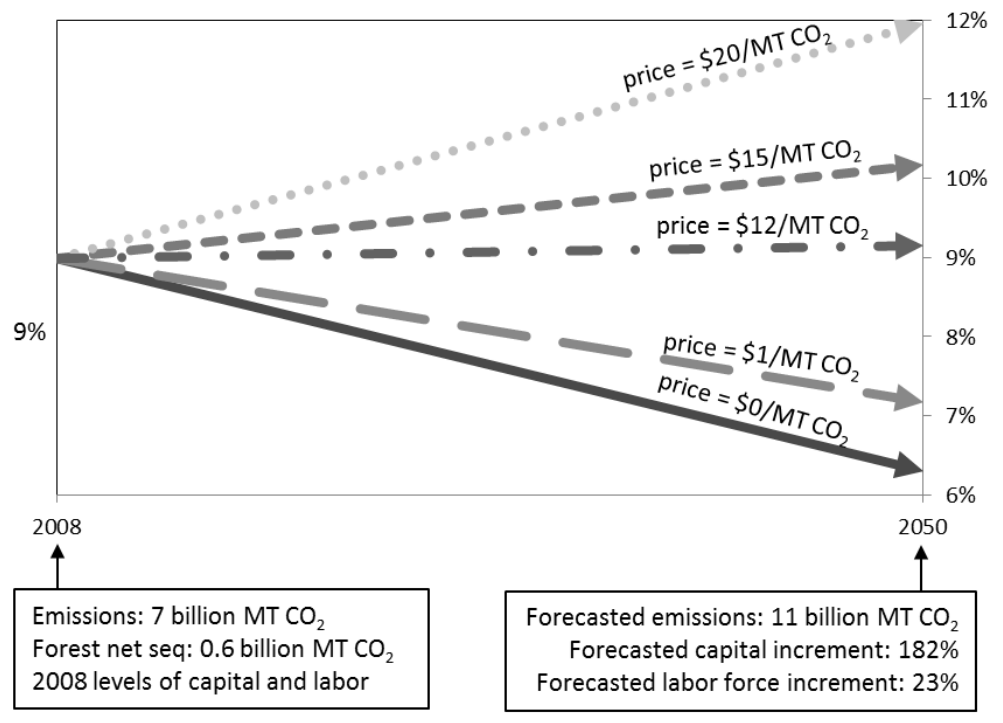

Figure 2: Net Forest-Based Carbon Sequestration as a Share of Total Annual Greenhouse Gas Emissions Under Different Carbon Offset Prices in 2008 and 2050

The previous results will be explained in more detail by listing the regional and national GHG removal contributions and emissions from different forest-related sinks and sources, respectively. Subsequently, the land-use and general equilibrium implications will be analysed. For brevity, the latter will be decomposed and analysed only for the highest offset price considered in this study (i.e. $\$ 20 / \mathrm{MT} \mathrm{CO}_{2}$ ).

\subsection{Regional and National GHG Removals}

Table 2 lists the annual carbon removals and emissions categorised by their respective sinks and sources for both 2008 and 2050 baselines and 2050 counterfactuals at the offset prices of $\$ 10$ and $\$ 20 / \mathrm{MT} \mathrm{CO}_{2} \cdot{ }^{23}$ By projecting labor and capital growth from 2008 up to 2050, baseline regional carbon removals by the commercial logging industry increased by $20 \%$ to 507 million $\mathrm{MT}$ of $\mathrm{CO}_{2}$. In the 2050 baseline, total projected national annual removals from forests and HWP amount to approximately 1,050 million MT of $\mathrm{CO}_{2}$. However, by estimating 2050 baseline annual emissions from domestic wood harvests of 369 million MT of $\mathrm{CO}_{2}$ and subtracting them from national removals, the 2050 baseline national removals decrease from a gross total of 1,050 million MT to a net total of 681 million $\mathrm{MT}$ of $\mathrm{CO}_{2}$ as shown in table 2.

By introducing a carbon offset price of $\$ 20 / \mathrm{MT} \mathrm{CO}_{2}$, simulating a carbon-intensive management regime by the commercial logging industry and introducing afforested set-asides; total projected national annual removals from forests and HWP increase by 824 million MT (or 78\%) to 1,874 million MT of $\mathrm{CO}_{2}$. However, the high carbon removal contributions resulting from a more carbon-intensive management regime adopted by the commercial logging industry are attained at the expense of higher emissions from domestic wood

\footnotetext{
${ }^{23}$ As previously mentioned, approximately $49 \%$ of the 857 million $\mathrm{MT}$ of $\mathrm{CO}_{2}$ removed nationally by all forestlands in 2008 were considered as the baseline annual removals by the commercial logging industry in the region in question (or 422 million MT of $\mathrm{CO}_{2}$ ). The remaining $51 \%$ of total 2008 removals (435 million MT of $\mathrm{CO}_{2}$ ) were assigned to the rest of the forestlands in the U.S. and left constant for the different scenarios.
} 
Table 2: Annual GHG Removals and Emissions (million $\mathrm{MT} \mathrm{CO}_{2} /$ year) From Forestry and HWP in the Baselines and with Two different Carbon Offset Prices $\left(\$ / \mathrm{MT} \mathrm{CO}_{2}\right)$

\begin{tabular}{|c|c|c|c|c|}
\hline \multirow{3}{*}{ Removal Sinks and Emissions Sources } & & & \multicolumn{2}{|c|}{2050 Afforestation } \\
\hline & \multicolumn{2}{|c|}{ Baselines } & \multicolumn{2}{|c|}{ Counterfactuals } \\
\hline & 2008 & 2050 & $\$ 10 / \mathrm{MT}$ & $\$ 20 / \mathrm{MT}$ \\
\hline Rest of U.S. Forestland & 435 & 435 & 435 & 435 \\
\hline Regional Aggregation & 422 & 507 & 722 & 1,200 \\
\hline Commercial Logging Industry & 422 & 507 & 705 & 871 \\
\hline Afforested Set-Asides & 0 & 0 & 17 & 329 \\
\hline National Harvested Wood Products & 78 & 108 & 179 & 238 \\
\hline In Use & 18 & 25 & 41 & 55 \\
\hline In Solid-Waste Disposal Sites & 60 & 83 & 138 & 183 \\
\hline Emissions From Domestic Wood Harvest & -319 & -369 & -484 & -582 \\
\hline U.S. Net Removals From Forestry and HWP & 616 & 681 & 851 & 1,292 \\
\hline Total U.S. GHG Emissions & 7,048 & 10,800 & 10,800 & 10,800 \\
\hline$\%$ of U.S. GHG Removed by Forest and HWP & $9 \%$ & $6 \%$ & $8 \%$ & $12 \%$ \\
\hline
\end{tabular}

harvests. Again, permanence can only be guaranteed from the afforested set-asides not from the commercial logging industry. Hence, 2050 annual emissions from domestic wood harvests increase by $58 \%$ to 582 million MT of $\mathrm{CO}_{2}$ resulting in net total removals of 1,292 million $\mathrm{MT}$ of $\mathrm{CO}_{2}$. Out of the 611-million-MT increment, $46 \%$ is attributed to the commercial logging industry and HWP, and 54\% to the afforested set-asides.

Following Stavins [54], carbon-offset supply curves were generated by subtracting the 2050 projected annual baseline offsets $(p c r b=0)$ from the annual offsets generated in the counterfactual equilibria $(p c r b>0)$. This additional offsets were plotted with their respective marginal costs or carbon-offset prices $(p c r b)$. Figure 3 shows the resulting general equilibrium carbon-offset supply curves generated for different GHG accounting levels to allow comparisons to previous literature. Previous studies have mostly generated gross supply curves including only removals whereas this study also considers emissions from domestic harvested wood products (i.e. net carbon-offset supply). The gross national supply curve from forests contains the horizontal summation of the supply curves generated by the afforested set-asides and the commercial logging industry under a carbon-intensive management regime. The gross forest and HWP supply curve contains also the supply curve generated by HWP in use and in SWDS. The net forest and HWP deducts the annual GHG emissions generated by domestic harvested wood products from private timberland. For an offset price of $\$ 20 / \mathrm{MT} \mathrm{CO}_{2}$, afforested set-asides and the commercial logging industry would supply 694 million MT of $\mathrm{CO}_{2}$ offsets additionally to the baseline in 2050. For the same price level, forests and HWP would supply 823 million MT of $\mathrm{CO}_{2}$ offsets additionally to the baseline in 2050. And by discounting the emissions produced by domestic HWP, forests and HWP would supply 611 million MT of $\mathrm{CO}_{2}$ offsets additionally to the baseline in 2050. Over half (54\%) of the additional net sequestration would be attributed to afforested set-asides. 


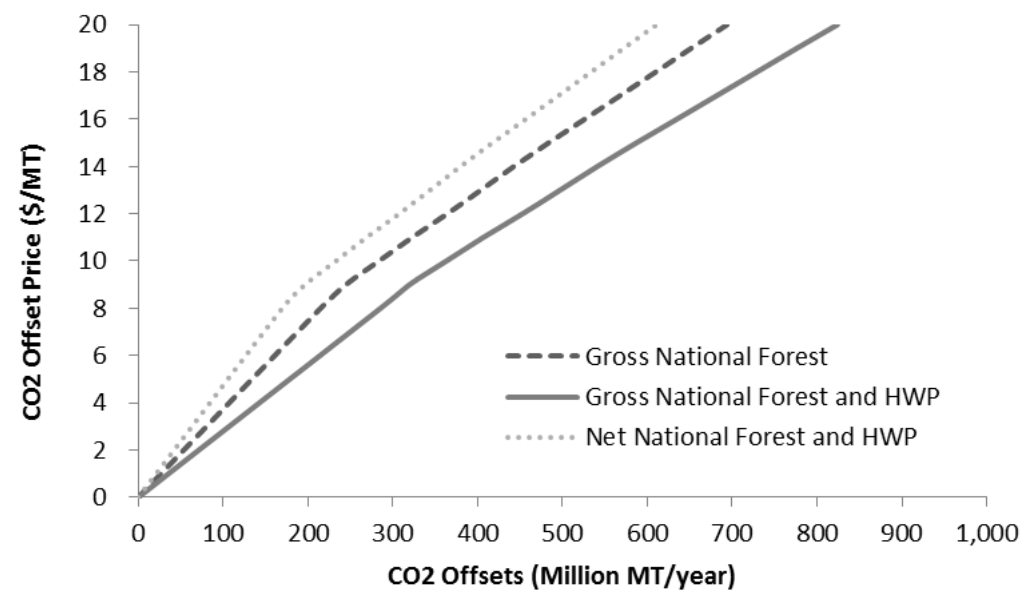

Figure 3: Forest-Based Additional Carbon-Offset Supply Curves Resulting From the Establishment of Afforested Set-Asides and the Adoption of a Carbon-Intensive Management Regime by the Commercial Logging Industry in 2050

\subsection{Land-Use Change Stimulated by Afforested Set-Asides}

Figure 4 depicts the magnitudes of the movements among land-use categories along the entire range of $\mathrm{CO}_{2}$-offset prices. ${ }^{24}$ At an offset price of $\$ 20 / \mathrm{MT} \mathrm{CO}_{2}$, the greatest percentage of land movement occurs in pastureland followed by cropland, losing approximately $15 \%$ and $8 \%$ of their 2050 baseline acreages, respectively. A total of 61 million acres are afforested and set-aside for carbon sequestration. From this figure, it is evident that set-asides become a feasible alternative at a carbon-offset price of $\$ 6 / \mathrm{MT} \mathrm{CO}_{2}$ and that pastureland is the land-use type most impacted by the set-asides due to its lower average rent ( $\$ 23 /$ acre) compared to cropland (\$75/acre) in the regional aggregation in 2008.

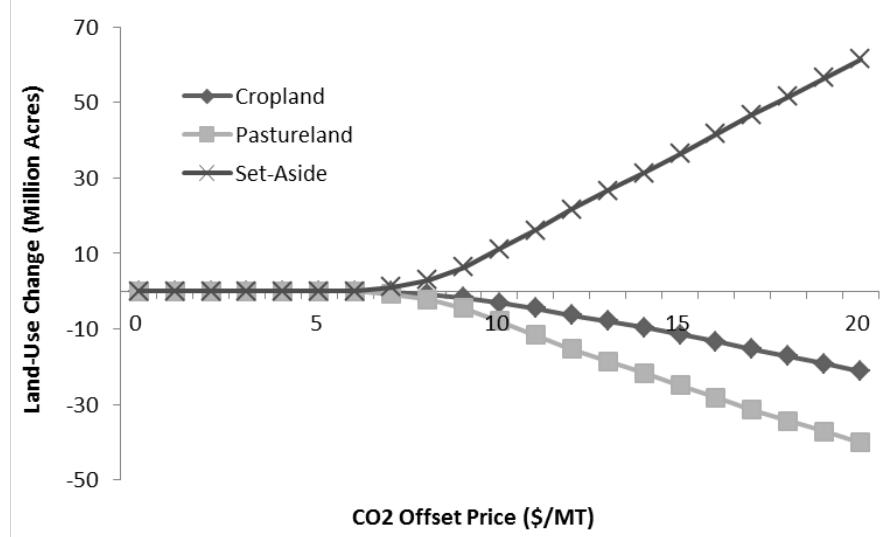

Figure 4: Total Land-Use Change Stimulated by the Establishment of Afforested Set-Asides for Different Carbon-Offset Prices in 2050

\footnotetext{
${ }^{24} \mathrm{CET}$ functions pose a challenge to comply with the additivity of physical acres. A standardisation approach detailed in appendix A was used to obtain absolute land-use change in physical acre units.
} 
Figure 5a shows the distribution of the afforested set-asides among the 166 MLRAs included in the regional aggregation at an offset price of $\$ 20 / \mathrm{MT} \mathrm{CO}_{2}$. Approximately $36 \%$ of the land set aside for carbon sequestration takes place in five MLRAs: the Central Rolling Red Plains, Eastern Part (covering Eastern OK, part of KS and North TX); the Rolling Soft Shale Plain (covering ND and SD); the Central Rolling Red Prairies (covering Central OK, part of KS and North TX); the Nebraska Sand Hills (covering NE); and the Central High Tableland (covering South NE, Eastern CO and Western KS). Out of the 329 million MT of $\mathrm{CO}_{2}$ sequestered by all set-asides at a price of $\$ 20 / \mathrm{MT} \mathrm{CO}_{2}, 195$ million $\mathrm{MT}$ of $\mathrm{CO}_{2}(59 \%)$ come from softwood forests and 133 million MT of $\mathrm{CO}_{2}$ (41\%) from hardwood forests.

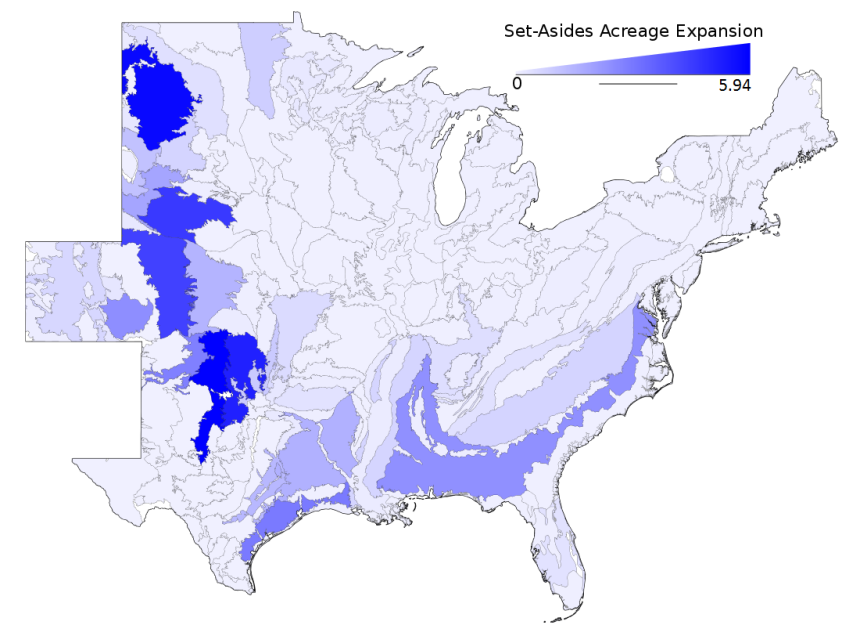

(a) Afforested Set-Asides Expansion

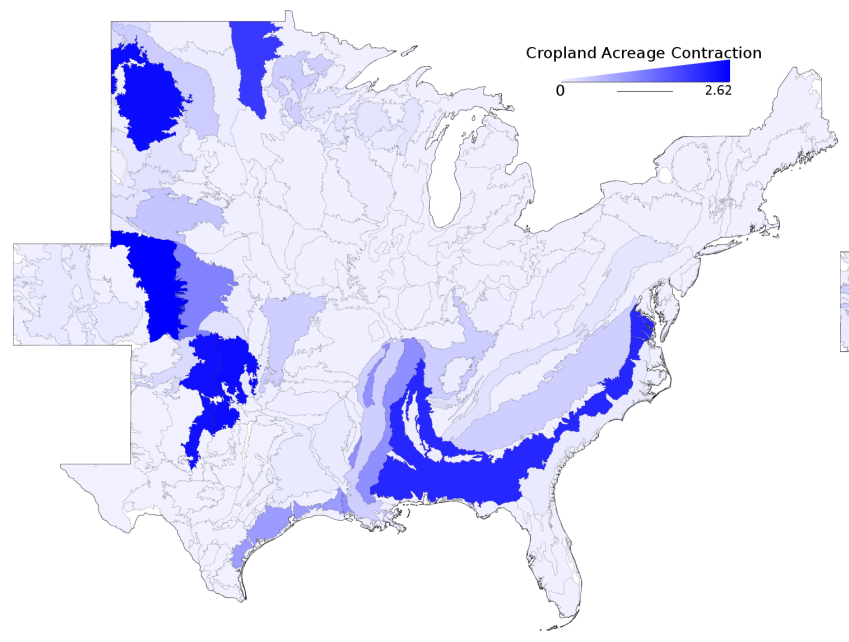

(b) Cropland Contraction

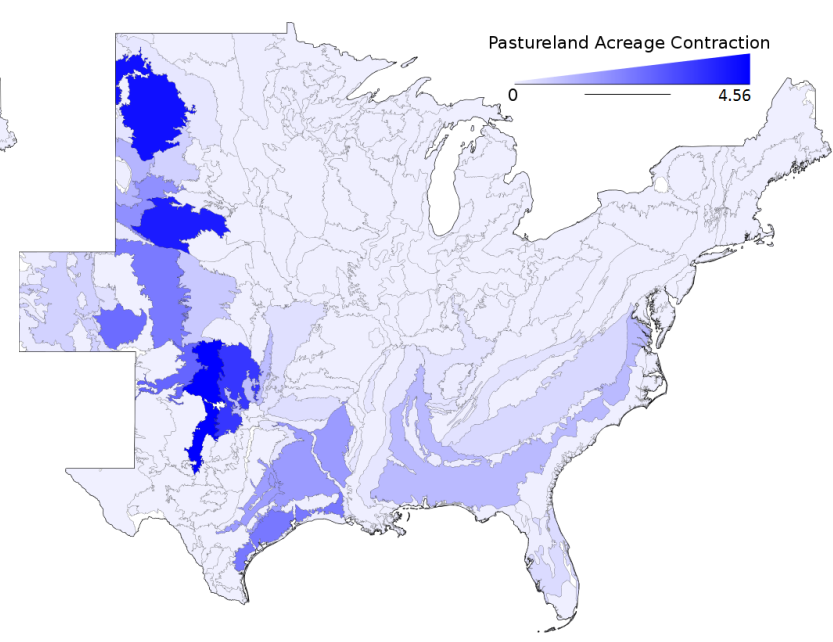

(c) Pastureland Contraction

Figure 5: Land-Use Change (Millions of Acres) in Different MLRAs Stimulated by the Establishment of Afforested Set-Asides at a Carbon-Offset Price of $\$ 20 / \mathrm{MT} \mathrm{CO}_{2}$ in 2050

As shown in figure 5b and 5c, the MLRAs with the highest cropland and pastureland acreage reduction are essentially the same ones with high set-aside afforestation activity at an offset price of $\$ 20 / \mathrm{MT}$ of $\mathrm{CO}_{2}$. Approximately $41 \%$ of all the land diverted from cropland takes place in the five previously mentioned 
MLRAs plus the Red River Valley of the North (covering East ND and West MN). Approximately $37 \%$ of all the land diverted from pastureland takes place in the five MLRAs with high set-aside acreage. Among the reasons for the high acreage diversion out of agriculture in these MLRAs are the high sequestration uptake rates in the regional aggregation, the lower afforestation costs and lower agricultural land rents.

\subsection{General Equilibrium}

As economists like to put it "there is no such thing as a free lunch." Although the supply of carbon offsets is high at a low carbon price; the general equilibrium effects on agricultural commodities look rather dim, especially for beef cattle.

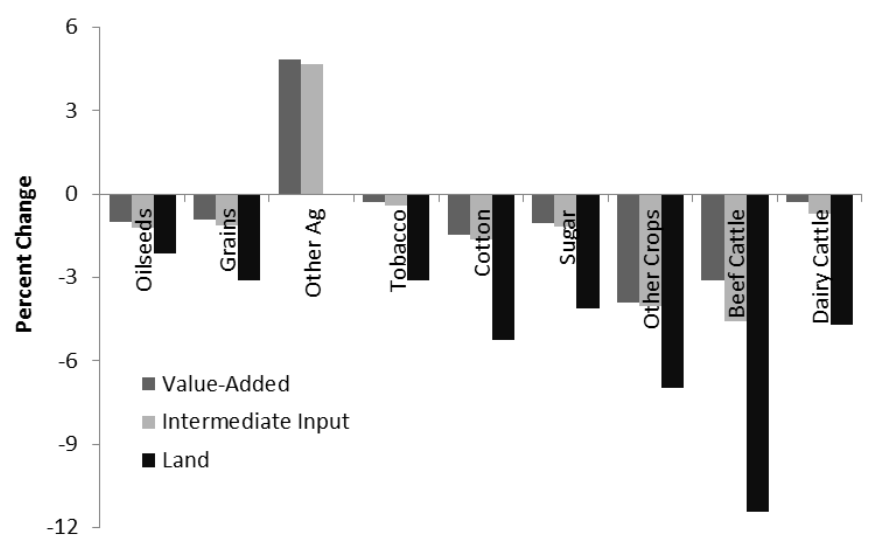

Figure 6: Percent Changes (wrt 2050 Baseline) of Agricultural Input Intensities Resulting from the Establishment of Afforested Set-Asides at a Carbon-Offset Price of $\$ 20 / \mathrm{MT} \mathrm{CO}_{2}$ in 2050

As shown in figure 6, agricultural industries substituted land out of production as a result of the agricultural land lost to afforestation. As expected, the high carbon offset price of $\$ 20 / \mathrm{MT} \mathrm{CO}_{2}$ drove land prices up resulting in acreage diversion from agricultural purposes. Due to the high land movement out of pastureland (40 million acres), the beef industry is the most affected one, decreasing its land use by $11 \%$. As expected, the use of land of the other crops commodity (including hay, alfalfa, clover and grasses) is also drastically affected (7\% reduction) as it heavily depends on the cattle industry. The high cropland contraction (21 million acres) taking place in the Southeast affected the cotton, sugarcane and tobacco industries by decreasing their land demand by $5 \%, 4 \%$, and $3 \%$, respectively. Since there is an almost negligible cropland contraction in the Midwest, oilseeds and grains (most important to the human diet) were not as heavily affected as others with their land demand only decreasing by $2 \%$ and $3 \%$, respectively. It is also evident from figure 6 that the drastic reduction in land is followed by a relatively slight reduction in the use of value-added (capital and labor) and intermediate inputs implying a degree of intensification of production per area unit (e.g. acre). This effect is more evident in the beef cattle industry where the use of value-added and intermediate inputs decreases less (3\% and $4 \%$ respectively) than land (11\%). As previously mentioned, the other agriculture aggregated industry includes afforestation services; hence, the increase of value-added and intermediate inputs follow the high demand for afforestation services. 


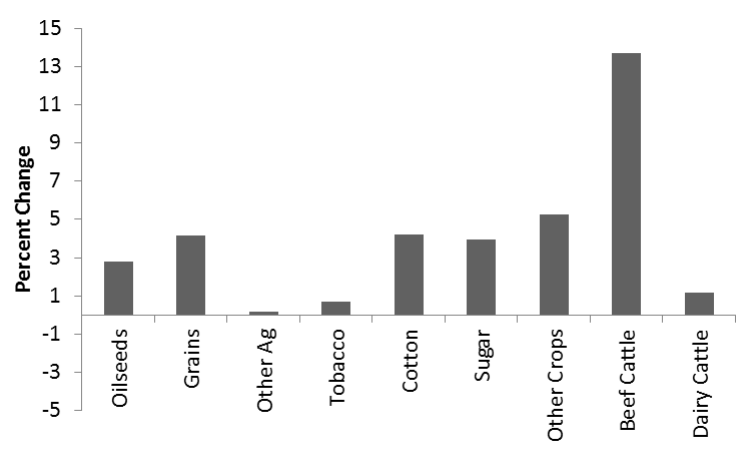

(a) Prices

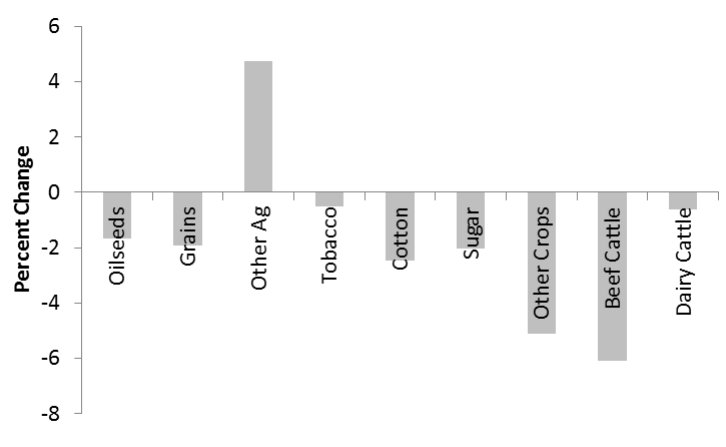

(b) Production

Figure 7: Percent Changes (wrt 2050 Baseline) of the Supply of Agricultural Commodities Resulting from the Establishment of Afforested Set-Asides at a Carbon-Offset Price of $\$ 20 / \mathrm{MT} \mathrm{CO}_{2}$ in 2050

The rising demand of agricultural commodities coupled with the reallocation of resources to the afforestation initiative results in a lower supply of agricultural commodities as shown in $7 \mathrm{~b}$. The price of the beef cattle commodity increases by approximately $14 \%$ as a result of the high pastureland afforestation as shown in 7 a. The dairy cattle industry was not as severely affected since it does not depend on pastureland to a great extent. ${ }^{25}$ The price of the other crops commodity was also one of the most affected ones with a price increment of $5 \%$ due to the land movement out of cropland and the lower demands from the cattle industry. The prices of oilseeds and grains were also impacted by the intensification effect with a $3 \%$ and $4 \%$ price increment, respectively. The general equilibrium effects on timber production were rather drastic due to the carbon-intensive management regime simulated by increasing the substitution of land for timber biomass. An offset price of $\$ 20 / \mathrm{MT} \mathrm{CO}_{2}$ resulted in an oversupply of timber increasing production by $72 \%$ and driving prices down by $43 \%$. However, the timber price drop is in part compensated by the new carbon payment revenue stream enjoyed by timber producers.

Figure 8 shows the percent reduction in agricultural exports to the rest of the world due to the low domestic production of agricultural products, as shown in figure $7 \mathrm{~b}$, and agricultural land diversion to afforestation. As expected, exports of the beef cattle commodity are impacted the most with a reduction of $8 \%$ due to the high pastureland diversion. The exports of oilseeds and grains would not be severely affected with a decrease of approximately $2 \%$ each. As a result of the carbon intensive regime, timber exports triple.

\section{Conclusions}

A comparative static regional CGE model was used to assess the long-run impacts of a forest-based carbon sequestration program on annual carbon removal contributions, land-use patterns and prices of competing

\footnotetext{
${ }^{25}$ According to MacDonald et al. [55], a small percentage of the dairy herd depends on pastureland, mainly dry cows and small dairy operations. Monge and Bryant [48] used the shares of grazing herds by operation size estimated by [56] to estimate the demand of pastureland from the dairy cattle industry.
} 


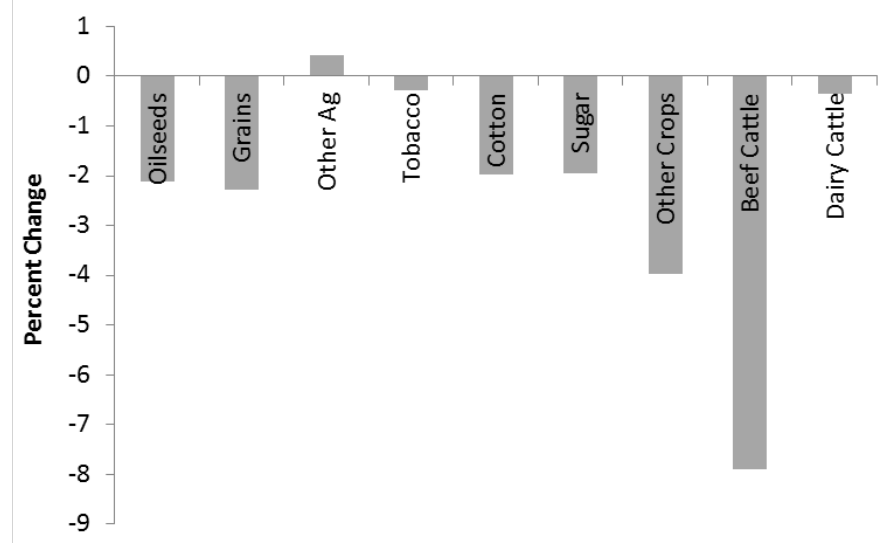

Figure 8: Percent Changes (wrt Baseline) of Agricultural Exports Resulting from the Establishment of Afforested Set-Asides at a Carbon-Offset Price of $\$ 10 / \mathrm{MT} \mathrm{CO}_{2}$

agricultural commodities in 2050. The forest sequestration activities modelled were afforested set-asides and a carbon-intensive management regime adopted by the commercial logging industry. A modified regional SAM was projected from 2008 to 2050 using capital and labor growth projections. By explicitly modelling the market for heterogeneous land, land-use change patterns were also identified among different MLRAs in the regional aggregation in question. The annual carbon removals and emissions from HWP derived from domestic harvests were also assessed.

Results show that by establishing afforested set-asides and adopting a carbon-intensive regime, a carbon offset price of $\$ 12 / \mathrm{MT} \mathrm{CO}_{2}$ would result in a forecasted forestry and HWP carbon sequestration percentage of $9 \%$ of total 2050 emissions - the same percentage observed in 2008 without a carbon price in place. For a carbon offset price of $\$ 20 / \mathrm{MT} \mathrm{CO}_{2}$, the carbon sequestration percentage would increase to $12 \%$ resulting in 611 million additional MT of $\mathrm{CO}_{2}$ (compared to the 2050 baseline) sequestered mainly by afforested set-asides planted with softwood species.

A high carbon offset price of $\$ 20 / \mathrm{MT} \mathrm{CO}_{2}$ would drive land prices up resulting in the diversion of approximately 61 million acres of agricultural land into forestland coming mainly from pastureland (40 million) followed by cropland (21 million). By including the land endowments in 166 MLRAs among three land-use types, the highest concentration of afforested set-asides was localised in the Central Plains from North Dakota to Northern Texas. The high movement from this region's pastureland is the result of the combination of low afforestation costs, low land rents and high uptake rates relative to the rest of the regions.

High land prices would force agricultural activities to intensify production systems using more capital and labor in smaller areas. The substitution of land for value-added inputs, would drive up the prices of agricultural commodities such as beef (14\%), oilseeds (3\%) and grains (4\%). Exports of all agricultural commodities to the rest of the world would decrease except for timber and the other agriculture commodity, which includes afforestation services. Timber exports would triple as the result of the carbon-intensive regime (more biomass per acre) adopted by the commercial logging industry. 
Table 3: Comparison of Carbon Sequestration Potential with Previous Studies Using Sector Optimisation Approaches at a Carbon Offset Price of $\$ 15 / \mathrm{MT} \mathrm{CO}_{2}$

\begin{tabular}{ccccc}
\hline Authors & Approach & Model & Coverage & $\begin{array}{c}\text { Potential } \\
\text { (million MT) }\end{array}$ \\
\hline This study & General Eq & & National & $483^{*}$ \\
Murray et al. [6] & Partial Eq & FASOMGHG & National & 356 \\
Sohngen [57] & Partial Eq & GTM & National & 210 \\
Golub et al. [15] & General Eq & GTAP-AEZ-GHG & National & 336 \\
Sedjo et al. [58] & Partial Eq & GTM & North America & 265 \\
\hline
\end{tabular}

*417 MT when considering GHG emissions from HWP.

As previously mentioned, the literature on the economic implications of a potential forest-based carbon policy is extensive as demonstrated by Richards and Stokes [9], van Kooten et al. [1], Stavins and Richards [2], and van Kooten and Sohngen [8]. However, to circumscribe the type and scope of the literature, Table 3 lists the most recent studies using different modalities of the sector optimisation approach in the U.S. Furthermore, the results in this study are not directly comparable to previous ones due to differences in scope (i.e. private forests in a subregion and national HWP) and in mechanisms considered (i.e. permanence from afforested set-asides and private timberland under intensive management). However, as listed in Table 3 by comparing the broad estimates from studies using two widely-cited sector optimisation models (FASOMGHG and GTM) and one CGE model (GTAP-AEZ-GHG), the results from this study suggest that GHG sequestration may prove less costly than previously believed.

For example Murray et al. [6] used FASOMGHG and estimated that 356 million $\mathrm{MT}$ of $\mathrm{CO}_{2}$ could be sequestered annually by afforestation (137 million) and forest management activities (219 million) for \$15/MT $\mathrm{CO}_{2}$ compared to the 483 million MT obtained in this study for the same price and similar mechanisms: 193 million from afforestation and 290 million from management intensity. Sedjo et al. [58] and Sohngen [57], using GTM, estimated that 265 million $\mathrm{MT}$ of $\mathrm{CO}_{2}$ and 210 million MT could be sequestered in North America and the U.S., respectively, for a price of approximately $\$ 15 / \mathrm{MT} \mathrm{CO}_{2}$. Golub et al. [15] used GTAPAEZ-GHG and estimated that for a price of approximately $\$ 15 / \mathrm{MT} \mathrm{CO}_{2}, 336$ million $\mathrm{MT}$ of $\mathrm{CO}_{2}$ would be sequestered as a result of afforestation (66 million) and management intensification (270 million). According to Sohngen and Brown [12], setting aside already existing forests for carbon sequestration becomes a feasible alternative at $\$ 41 / \mathrm{MT}$ of $\mathrm{CO}_{2}$ whereas afforested set-asides become feasible at $\$ 6 / \mathrm{MT}$ in this study.

Although a set of carbon offset supply schedules were estimated, this study has not considered the costs of implementing, enforcing and evaluating the outcomes of an afforestation program. The assessment of the carbon sequestered in existing private timberland would definitely add a burden to the budget allocated by the government. Enforcement is also an important factor since if the afforestation program was implemented, prohibiting timber harvest from the set-asides might require substantial funding. Although this study focuses on a forest-based carbon sequestration program, the results obtained could easily be coupled to other national general equilibrium models that consider the entire array of GHG sources and sinks from different industries under a carbon cap-and-trade market structure. 
Technological change and the resulting yield growth potential experienced in the agricultural sector has been identified to be a critical factor when analysing the land-use effects of biofuel and GHG abatement policies [59]. Considering the context of this study, such technological change would potentially result in more land availability for the forest-based carbon sequestration implying lower offset costs. Although such hypothesis is well worth a further and more detailed scrutiny, it is beyond the scope of this exercise. Hence, such technological consideration in the agricultural sector would be a nice extension to the exercise presented in this article. 


\section{References}

[1] G. C. van Kooten, A. J. Eagle, J. Manley, T. Smolak, How costly are carbon offsets? a meta-analysis of carbon forest sinks, Environmental Science and Policy 7 (2004) 239-251.

[2] R. N. Stavins, K. R. Richards, The Cost of U.S. forest-based Carbon Sequestration, Technical Report, Pew Center on Global Climate Change, 2005.

[3] Environmental Protection Agency (EPA), Inventory of U.S. Greenhouse Gas Emissions and Sinks: 19902011, Technical Report, U.S. Environmental Protection Agency, 1200 Pennsylvania Ave., N.W. Washington, DC 20460 U.S.A., 2013.

[4] R. N. Lubowski, A. J. Plantinga, R. N. Stavins, Land-use change and carbon sinks: Econometric estimation of the carbon sequestration supply function, Journal of Environmental Economics and Management 51 (2006) 135-152.

[5] J. Lewandrowski, M. Peters, C. Jones, R. House, M. Sperow, M. Eve, K. Paustian, Economics of Sequestering Carbon in the U.S. Agricultural Sector, Technical Bulletin 1909, Economic Research Service, U.S. Department of Agriculture, Washington, D.C., 2004.

[6] B. C. Murray, B. Sohngen, A. J. Sommer, B. Depro, K. Jones, B. McCarl, D. Gillig, B. DeAngelo, K. Andrasko, Greenhouse Gas Mitigation Potential in U.S. Forestry and Agriculture, Technical Report 430-R-05-006, Office of Atmospheric Programs, U.S. Environmental Protection Agency, Washington, D.C., 2005. URL: http://www.epa.gov/sequestration/greenhouse_gas.html.

[7] R. A. Birdsey, Changes in Forest Carbon Storage from Increasing Forest Area and Timber Growth, volume 1: Opportunities for Increasing Forest Cover of Forests and Global Change, American Forests, Washington, D.C., 1992, pp. 23-39.

[8] G. C. van Kooten, B. Sohngen, Economics of Forest Ecosystem Carbon Sinks: A Review, Working Paper 2007-02, Resource Economics and Policy Analysis (REPA) Research Group, Department of Economics, University of Victoria, 2007.

[9] K. R. Richards, C. Stokes, A review of forest carbon sequestration cost studies: A dozen years of research, Climatic Change 63 (2004) 1-48.

[10] B. C. Murray, B. A. McCarl, H.-C. Lee, Estimating leakage from forest carbon sequestration programs, Land Economics 80 (2004) 109-124.

[11] S. Walker, B. Sohngen, S. Grimland, J. Winsten, S. Brown, Carbon Supply from Sequestration Activities on Agriculture and Forest LLand for the SECARB Partnership, Report to: US Department of Energy, Southeast Regional Carbon Sequestration Partnership, Winrock International, 2005. 
[12] B. Sohngen, S. Brown, Extending timber rotations: Carbon and cost implications, Climate Policy 8 (2008) 435-451.

[13] B. Sun, B. Sohngen, Set-asides for carbon sequestration: Implications for permanence and leakage, Climatic Change 96 (2009) 409-419.

[14] T. G. Foley, D. d. Richter, C. S. Galik, Extending rotation age for carbon sequestration: A cross-protocol comparison of North American forest offsets, Forest Ecology and Management 259 (2009) 201-209.

[15] A. Golub, T. W. Hertel, H.-L. Lee, S. Rose, B. Sohngen, The opportunity cost of land use and the global potential for greenhouse gas mitigation in agriculture and forestry, Resource and Energy Economics 31 (2009) 299-319.

[16] M. Michetti, R. Rosa, Afforestation and timber management compliance strategies in climate policy. a computable general equilibrium analysis, Ecological Economics 77 (2012) 139-148.

[17] K. E. Skog, Sequestration of carbon in harvested wood products for the United States, Forest Products Journal 58 (2008) 56-72.

[18] R. Alig, D. Adams, B. McCarl, Ecological and economic impacts of forest policies: Interactions across forestry and agriculture, Ecological Economics 27 (1998) 63-78.

[19] D. Adams, R. Alig, B. McCarl, J. Callaway, S. Winnett, Minimum cost strategies for sequestering carbon in forests, Land Economics 75 (1999) 360-374.

[20] B. Sohngen, R. Mendelsohn, R. Sedjo, Forest management, conservation, and global timber markets, American Journal of Agricultural Economics 81 (1999) 1-13.

[21] B. Sohngen, R. Mendelsohn, An optimal control model of forest carbon sequestration, American Journal of Agricultural Economics 85 (2003) 448-457.

[22] B. Sohngen, R. Sedjo, Carbon sequestration in global forests under different carbon price regimes, Energy Journal 27 (2006) 109-126.

[23] B. Sohngen, R. Mendelsohn, Human-Induced Climate Change: An Interdisciplinary Assessment, New York, NY: Cambridge University Press, 2007, pp. 227-237.

[24] B. Kretschmer, S. Peterson, Integrating bioenergy into computable general equilibrium models: A survey, Energy Economics 32 (2010) 673-686.

[25] R. Darwin, M. Tsigas, J. Lewandrowski, A. Raneses, World Agricutlure and Climate Change: Economic Adaptations, Agricultural Economic Report 703, Economic Research Service, U.S. Department of Agriculture, 341 Victory Drive. Herndon, VA, U.S.A., 1995. 
[26] R. Darwin, M. Tsigas, J. Lewandrowski, A. Raneses, Land use and cover in ecological economics, Ecological Economics 17 (1996) 157-181.

[27] Natural Resource Conservation Service (NRCS), Land Resource Regions and Major Land Resource Areas of the United States, the Caribbean, and the Pacific Basin, USDA Handbook 296, U.S. Department of Agriculture, 2006. URL: ftp://ftp-fc.sc.egov.usda.gov/NSSC/Ag_Handbook_296/Handbook_296_low.pdf.

[28] S. Paltsev, J. M. Reilly, H. D. Jacoby, A. C. Gurgel, G. E. Metcalf, A. P. Sokolov, J. F. Holak, Assessment of us ghg cap-and-trade proposals, Climate Policy 8 (2008) 395-420.

[29] S. Paltsev, J. M. Reilly, H. D. Jacoby, J. F. Morris, The cost of climate policy in the united states, Energy Economics 31 (2009) S235-S243.

[30] B. Sohngen, A. Golub, T. W. Hertel, The role of forestry in carbon sequestration in general equilibrium models, in: T. W. Hertel, S. Rose, R. S. J. Tol (Eds.), Economic Analysis of Land Use in Global Climate Change Policy, 1 ed., Routledge, 2009.

[31] J. J. Monge, Long-Run Implications of a Forest-Based Carbon Sequestration Policy on the United States Economy: A Computable General Equilibrium (CGE) Modeling Approach, Ph.D. thesis, Texas A\&M University, College Station, Texas, 2012.

[32] H. Lofgren, R. L. Harris, S. Robinson, M. Thomas, M. El-Said, A Standard Computable General Equilibrium (CGE) Model in GAMS, Microcomputers in Policy Research 5, International Food Policy Research Institute, 2033 K Street, N.W., Washington, D.C., 20006-1002, U.S.A., 2002.

[33] H. L. Bryant, J. L. Campiche, J. Lu, A Static Computable General Equilibrium Model of World Energy and Agricultural Markets (WEAM), AFPC Research Paper 11-1, Agricultural and Food Policy Center, Texas A\&M University, College Station, Texas, 2011.

[34] J. J. Monge, H. L. Bryant, D. P. Anderson, Development of regional social accounting matrices with detailed agricultural land rent data and improved value-added components for the usa, Economic Systems Research 26 (2014) 486-510.

[35] P. Dixon, M. Rimmer, Dynamic General Equilibrium Modelling for Forecasting and Policy: A Practical Guide and Documentation of MONASH, Contributions to Economic Analysis, Elsevier, 2002.

[36] F. Bosello, R. Roson, R. S. J. Tol, Economy-wide estimates of the implications of climate change: Sea level rise, Environmental and Resource Economics 37 (2007) 549-571.

[37] A. Bigano, F. Bosello, Economy-wide impacts of climate change: a joint analysis for sea level rise and tourism, Mitigation and Adaptation Strategies for Global Change 13 (2008) 765-791. 
[38] M. Toossi, A century of change: The u.s. labor force, 1950-2050, Monthly Labor Review May (2002) $15-28$.

[39] P. S. Dee, Modelling steady state forestry in a computable general equilibrium context, Working Paper No. 91/8, National Centre for Development Studies, Canberra, Australia, 1991.

[40] Forest Service (FS), Forest inventory data online (fido), http://fiatools.fs.fed.us/fido/index.html (accesed December 2010), 2010.

[41] Y. Wei, D. J. Hayes, M. M. Thornton, W. M. Post, R. B. Cook, P. Thornton, A. Jacobson, D. N. Huntzinger, T. O. West, L. S. Heath, B. McConkey, G. Stinson, W. Kurz, B. de Jong, I. Baker, J. Chen, F. Chevallier, F. Hoffman, A. Jain, R. Lokupitiya, D. A. McGuire, A. Michalak, G. G. Moisen, R. P. Neilson, P. Peylin, C. Potter, B. Poulter, D. Price, J. Randerson, C. Rodenbeck, H. Tian, E. Tomelleri, G. van der Werf, N. Viovy, J. Xiao, N. Zeng, M. Zhao, Nacp regional: National greenhouse gas inventories and aggregated gridded model data, Web dataset, 2013. URL: http://dx.doi.org/10.3334/ORNLDAAC/1179.

[42] D. J. Hayes, D. P. Turner, G. Stinson, A. D. McGuire, Y. Wei, T. O. West, L. S. Heath, B. Dejong, B. G. McConkey, R. A. Birdsey, W. A. Kurz, A. R. Jacobson, D. N. Huntzinger, Y. Pan, W. M. Post, R. B. Cook, Reconciling estimates of the contemporary north american carbon balance among terrestrial biosphere models, atmospheric inversions, and a new approach for estimating net ecosystem exchange from inventory-based data, Global Change Biology 18 (2012) 1282-1299.

[43] T. W. Hertel, H.-L. Lee, S. Rose, B. Sohngen, Modeling land-use related greenhouse gas sources and sinks and their mitigation potential, in: T. W. Hertel, S. Rose, R. S. J. Tol (Eds.), Economic Analysis of Land Use in Global Climate Change Policy, 1 ed., Routledge, 2009.

[44] T. W. Hertel, A. Golub, A. D. Jones, M. O'hare, R. Plevin, D. M. Kammen, Effects of US maize ethanol on global land use and greenhouse gas emissions: Estimating market-mediated responses, BioScience 60 (2010) 223-231.

[45] N. B. Villoria, A. Golub, D. Byerlee, J. Stevenson, Will yield improvements on the forest frontier reduce greenhouse gas emissions? a global analysis of oil palm, American Journal of Agricultural Economics Online (2013) 1-8.

[46] S. A. Ahmed, T. W. Hertel, R. Lubowski, Calibration of a Land Cover Supply Function Using Transition Probabilities, GTAP Research Memorandum 14, Center for Global Trade Analysis, Purdue University, 2008.

[47] R. N. Lubowski, Determinants of Land-Use Transitions in the United States: Econometric Analysis of Changes Among the Major Land-Use Categories, Ph.D. thesis, Harvard University, 2002. 
[48] J. J. Monge, H. L. Bryant, A County-Level Land Rent Database for U.S. Agriculture and Forestry, AFPC Research Report 13-1, Agricultural and Food Policy Center, College Station, TX, 2013. URL: http://www . afpc.tamu .edu/pubs/2/583/RR-13-1-Land-Rent-Database.pdf.

[49] National Agricultural Statistics Service (NASS), Quick stats, http://quickstats.nass.usda.gov/ (accessed February 2011), 2011. URL: http://quickstats.nass.usda.gov/.

[50] Natural Resource Conservation Service (NRCS), Livestock nutrition, husbandry, and behavior, in: National Range and Pasture Handbook, 2 ed., U.S. Department of Agriculture, 1997. URL: ftp://ftp-fc.sc.egov.usda.gov/GLTI/technical/publications/nrph/nrph-ch6.pdf, revised on Dec 2003.

[51] B. Sohngen, Global timber market and forestry data project, http://aede.osu.edu/programs-and-research/forests-and-land-use/global-timbermarket-and-forestry-data-project (accessed March 2013), 2013. URL: http://aede.osu.edu/programs-and-research/forests-and-land-use/global-timber-market-and-forestry-da

[52] R. Moulton, K. Richards, Costs of Sequestering Carbon through Tree Planting and Forest Management in the United States, General Technical Report wo-58, U.S. Department of Agriculture, Washington, D.C., 1990.

[53] L. S. Bair, R. J. Alig, Regional Cost Information for Private Timberland Convertion and Management, General Technical Report PNW-GTR-684, U.S. Department of Agriculture, Forest Service, Pacific Northwest Research Station, 2006. URL: http://www.fs.fed.us/pnw/pubs/pnw_gtr684.pdf.

[54] R. N. Stavins, The costs of carbon sequestration: A revealed-preference approach, American Economic Review 89 (1999) 994-1009.

[55] J. M. MacDonald, E. J. O’Donoghue, W. D. McBride, R. F. Nehring, C. L. Sandretto, R. Mosheim, Profits, Costs, and the Changing Structure of Dairy Farming, Economic Research Report 47, Economic Research Service, U.S. Department of Agriculture, 2007. URL: http://www.ers.usda.gov/publications/err47/err47.pdf.

[56] Wisconsin Agricultural Statistics Service, Wisconsin Dairy Grazing Operations 2004 and 2009, Technical Report, National Agricultural Statistics Service, U.S. Department of Agriculture in cooperation with WI Department of Agriculture, Trade and Consumer Protection, 2005.

[57] B. Sohngen, Marginal Cost Curves for Carbon Sequestration in Forests: Estimates for Boreal, Temperate, and Tropical Regions of the World, Working Paper, AED Economics, Ohio State University, 2005.

[58] R. Sedjo, B. Sohngen, R. Mendelsohn, Estimating Carbon Supply Curves for Global Forests and Other Land Uses, Discussion Paper 01-19, Resources for the Future, Washington, D.C., 2001. 
[59] R. Keeney, T. W. Hertel, The indirect land use impacts of united states biofuel policies: The importance of acreage, yield, and bilateral trade responses, American Journal of Agricultural Economics 91 (2009) 895-909.

[60] J. Burniaux, T. P. Truong, GTAP-E: An Energy-Environmental Version of the GTAP Model, GTAP Technical Paper 16, Center for Global Trade Analysis, Purdue University, West Lafayette, Indiana, USA, 2002.

[61] T. W. Hertel, R. A. McDougall, B. Narayanan, A. H. Aguiar, Global Trade, Assistance, and Production: The GTAP 7 Data Base, Center for Global Trade Analysis, Purdue University, 2008, p. 18.

[62] ERS, USDA, International food consumption patterns, http://www.ers.usda.gov/dataproducts/international-food-consumption-patterns.aspx\#.VEgyb4f1bVQ (updated August 2014), 2005.

[63] T. W. Hertel, D. Hummels, M. Ivanic, R. Keeney, How confident can we be of CGE-based assessments of free trade agreements, Economic Modelling 24 (2007) 611-635.

[64] P. S. Armington, A Theory of Demand for Products Distinguished by Place of Production, International Monetary Fund Staff Papers 16, International Monetary Fund, 1969. 


\section{Appendix A: CGE Model Specification}

The CGE model relies on a nesting structure based on constant returns to scale, nested constant elasticity of substitution (CES) functions. The CES functions used encompass the two generally-used-by-convention limiting cases: Leontief and Cobb-Douglass. The structure of the general CES function is the following: ${ }^{26}$

$$
Q Y=\varphi\left(\sum_{i} \varsigma_{i}^{\frac{1}{\sigma}} Q X_{i}^{\frac{\sigma-1}{\sigma}}\right)^{\frac{\sigma}{\sigma-1}}
$$

where $i$ represents the inputs going into the function (intermediate commodities and factors), $\sigma$ is the exogenously-determined elasticity of substitution between inputs, $\varsigma$ is the share parameter for each input, $\varphi$ is the scale parameter (i.e. constant defining units of measurement), $Q Y$ is output quantity, and $Q X$ is input quantity. ${ }^{27}$ The elasticities used in the model are listed in table A.1. In standard CGE models $Q Y$ and $Q X$ come directly from the SAM as dollar values and prices are assumed to be unity in the baseline. Nevertheless, for this study we employ actual per-acre rents and acreage as the baseline land prices and quantities, respectively. The rest of the commodities and factors employ standard abstract units for quantities. The reason to include actual acreages is to track absolute, as opposed to relative, land movements between land-use categories in acres.

Table A.1: Substitution and Transformation Elasticities Used and Their Respective Sources

\begin{tabular}{|c|c|c|c|c|c|}
\hline Elasticity & Value & Source & Elasticity & Value & Source \\
\hline$\sigma_{L B}$ & -.02 & [46] & $\overline{\sigma_{J P}}$ & 0 & \\
\hline$\sigma_{L A}$ & -1.9 & [46] & $\sigma_{A T}$ & $0.2-1.3$ & [60] \\
\hline$\sigma_{L C}$ & -3 & [46] & $\sigma_{A V}$ & $0.2-1.3$ & [61] and [15] \\
\hline$\sigma_{L P}$ & -3 & [46] & $\sigma_{A L}$ & 0.5 & [43] and [59] \\
\hline$\sigma_{H T}$ & 0.4 & [62] & $\sigma_{A I}$ & $0-0.5$ & [60] \\
\hline$\sigma_{H C}$ & 0 & & $\sigma_{A C}$ & 1.26 & [15] \\
\hline$\sigma_{C D}$ & -2.5 & [61] & $\sigma_{A F T}$ & 0 & \\
\hline$\sigma_{C I}$ & $3.7-9.5$ & [63] & $\sigma_{A F I}$ & 0 & \\
\hline$\sigma_{C E}$ & -2.5 & [61] & $\sigma_{A F L}$ & 0 & \\
\hline$\sigma_{C T}$ & $0.9-4.7$ & [61] & & & \\
\hline
\end{tabular}

As shown in figure A.1, the CGE model reflects production activities as a set of top nests $(A T)$ that use as inputs the bundles produced by an intermediate input nest $(A I)$, a land nest for agricultural industries $(A L)$ and a value-added nest reflecting the demand of primary factors $(A V)$. The model includes a joint production nest $(J P)$ to consider the possibility of producing more than one output. As shown in figure A.1, activities form a land composite $(A L)$ from the different MLRAs where imperfect substitution is accounted for with a positive $\sigma .^{28}$

\footnotetext{
${ }^{26}$ The constant elasticity of transformation (CET) function was used to simulate transformation rather than substitution. The only difference in the specification of a CES and a CET function is the sign of $\sigma$. A positive sign implies a CES function, a negative sign a CET function.

${ }^{27}$ For a CET function, $\sigma$ is the exogenously-determined elasticity of transformation between outputs, $Q Y$ is input quantity, and $Q X$ is output quantity

${ }^{28}$ As previously mentioned, the prices and quantities are per-acre rents and acreage, respectively. Nevertheless, for the top
} 


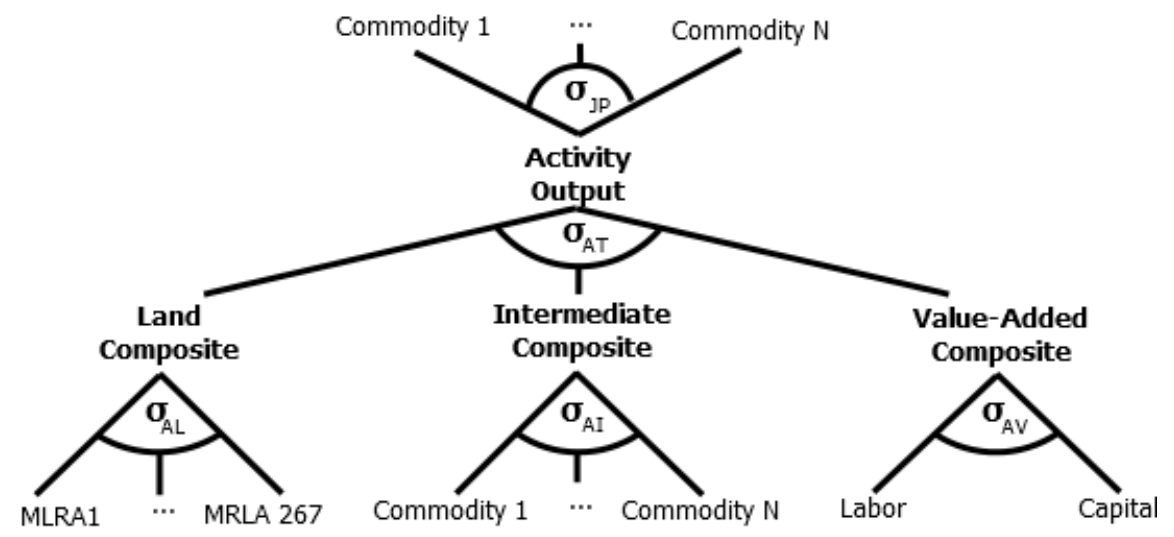

Figure A.1: Representation of production activities in the CGE model

To reflect rent and transformability differences among the alternative land uses, land supply has been divided into three nesting levels as depicted in the lower left dotted square of figure 1: 1) a nest $(L B)$ that supplies land from every MLRA $(l)$ to forestry $\left(A L_{a l g}\right)$ and agricultural land $(L A)$ as formulated in equations A.2 and A.3, respectively; 2$)$ a nest within agriculture $(L A)$ that supplies land to crop- $(L C)$ and pasturerelated $(L P)$ activities as formulated in equations A.4 and A.5, respectively; and 3) two nests, one within cropland $(L C)$ and one within pastureland $(L P)$, that supply land to all the agricultural activities $\left(A L_{a c r}\right.$ for cropland and $A L_{\text {aps }}$ for pastureland) as formulated in equations A.6 and A.7, respectively. Once land heterogeneity and transformability have been reflected in the model, land in each alternative use is assumed homogeneous. Land prices for forestry $(P L F)$, the agriculture bundle $(P Y L A)$, the crop bundle $(P Y L C)$, the pasture bundle $(P Y L P)$, individual crops $(P L C)$, and individual activities demanding pastureland $(P L P)$ are estimated as the shadow prices of the mixed complementarity relationships. To include afforested setasides, equations A.4 and A.5 would be substituted by equations 4 and 5, respectively.

$$
\begin{gathered}
Q X L B_{l,,^{\prime} f r l d^{\prime}} \geq Q X A L_{a l g, l} \perp P L F_{l} \\
Q X L B_{l,^{\prime} a g l d^{\prime}} \geq Q Y L A_{l} \perp P Y L A_{l} \\
Q X L A_{l,^{\prime} c r l d^{\prime}} \geq Q Y L C_{l} \perp P Y L C_{l} \\
Q X L A_{l,,^{\prime} p s l d^{\prime}} \geq Q Y L P_{l} \perp P Y L P_{l} \\
Q X L C_{l, a c r} \geq Q X A L_{a c r, l} \perp P L C_{a c r, l} \\
Q X L P_{l, a p s} \geq Q X A L_{a p s, l} \perp P L P_{a p s, l}
\end{gathered}
$$

The CETs used for the first two nests $(L B$ and $L A$ ), were estimated from own-return elasticities by following the procedure used by Hertel et al. [44] and Villoria et al. [45] and developed by Ahmed et al. [46]. ${ }^{29}$

nest $(A T)$ in the baseline, the land composite input price is unity and its quantity is the product of the $A L$ input price and quantity.

${ }^{29}$ All own-return elasticities were obtained from Ahmed et al. [46]. A 50-year horizon was assumed for the own-return 
The CETs used were -0.02 and -1.96 for the $L B$ and $L A$ nests, respectively. The $L B$ CET obtained from the procedure developed by Ahmed et al. [46] was too high (-2.02) due to the high transformability between crop and pastureland. Hence, the LB CET used (-0.02) was the one adjusted with the own-return elasticity of forestland, which was considered low enough to represent the low transformability between forestland and agricultural land. ${ }^{30}$ The CETs for $L C$ and $L P$ were set at -3 to reflect a higher transformability.

CET functions pose a challenge to comply with the additivity of physical acreage. Hence, a standardisation of resulting land-use change was achieved by estimating the land cover percentages by MLRA from the solution levels and multiplying them by the constant absolute MLRA endowment (in acres) in the following manner:

$$
\begin{aligned}
& \text { LandCount }_{\text {use }, l}=Q X L B_{\text {use }, l}^{\text {count }} / \sum_{\text {use }} \sum_{l} Q X L B_{\text {use }, l}^{\text {count }}, \\
& \text { LandBase }_{\text {use }, l}=Q X L B_{\text {use }, l}^{\text {base }} / \sum_{\text {use }} \sum_{l} Q X L B_{\text {use }, l}^{\text {base }}, \\
& \text { StdLandCount }_{\text {use }, l}=q l_{l} * \text { LandCount }_{\text {use }_{l},}, \\
& \text { StdLandBase } e_{u s e, l}=q l_{l} * \text { LandBase }_{\text {use }, l}, \\
& L U C_{u s e, l}=S t d L a n d C o u n t_{u s e, l}-\text { StdLandBase }_{u s e, l},
\end{aligned}
$$

where $u s e$ is a set comprised of ' $f r l d$ ' and 'agld'; $l$ represents the MLRAs; $q l$ the fixed land endowments; the count and base superscripts representing the counterfactual and baseline scenarios; and $L U C$ represents land-use change in physical acres.

Factors of production $(f)$ are assumed immobile across the region under study and outside regions. However, they are assumed to be mobile across activities. Hence, the model generates long-run equilibria under the different parametrical shocks. The endowments of each primary factor $(q f)$ and land category (MLRA) ( $q l$ ) are fixed and taken directly from the base-year SAM as shown in equations (A.13) and (A.14), respectively:

$$
\begin{gathered}
q f_{f} \geq \sum_{a} Q X A V_{a, f} \perp P f_{f}, \\
q l_{l} \geq Q Y L B_{l} \perp P l_{l} .
\end{gathered}
$$

Estimated factor prices (or wage) and land rents are assumed to be the same across activities for each factor and MLRA, respectively. Each estimated factor price and land rent vary to ensure factor and land market clearance. Factor income after taxes and depreciation (in the case of capital) and land rents (according to [34]) are distributed among the different households and a single representative enterprise.

\footnotetext{
elasticity for forestland (0.02), cropland (0.27) and pastureland (0.44). The own-return elasticity for agricultural land (0.35) was estimated as the average between cropland and pastureland.

${ }^{30}$ Some MLRAs resulted in negligible land movements from forestland to the set-asides. Since we do not consider reforested set-asides in this study, the $L B$ CETs of these MLRAs were set to zero without affecting the results. The elasticities of some MLRAs were also set lower due to the small rent payments coming from the commercial logging industry.
} 
As reflected in the SAM, there are 9 household categories $(h)$ based on annual income. Households and enterprises are endowed with primary factors of production $(q f)$ and land $(q l)$. These endowments are assumed to be fixed to the observed base-year quantities. As formulated in equation A.15, households' incomes $(H I)$ are partially generated by the sale $(h s)$ of commodities $(c)$ at producer's prices $(P Q)$. The volume of the sales is fixed at the base year quantity. Households receive a share $(\beta)$ of the net income received $(F I)$ by primary factors $(f)$, valued at their respective wage $(W F)$, from renting them to the production activities. They receive a share $(\gamma)$ of the income from the land, in different MLRAs $(l)$, rented to agricultural activities at their respective rental rates $(W L)$. Households also receive a share $(\delta)$ of the government's $(g)$ transferable income $(G T)$, a share $(\epsilon)$ of enterprises' transferable income $(E T)$, a share $(\zeta)$ of the investment account's transferable income $(I T)$ and transfers $(\eta)$ from outside regions $(t)$. The transfers coming from the investment account are considered borrowed capital for consumption. As shown in equation A.16, factor income transferred to households and enterprises $(F I)$ is net of factor taxes $(t f)$ and depreciation $(d p)$ in the case of capital. Households' incomes are subject to a tax $(t h)$ imposed by the government. As formulated in equation A.17, after accounting for income taxes, a portion of the income $(H T)$ is transferred to other institutions and, also, devoted to consumption and savings. After accounting for transfers to other households $(\alpha)$ and to outside regions $(\theta)$, the net income $(H N)$ devoted to commodity consumption and savings is formulated as in equation A.18.

$$
\begin{gathered}
H I_{h}=\left(\sum_{c} h s_{h, c} * P Q_{c}\right)+\left(\sum_{f} F I_{f} * W F_{f} * \beta_{h, f}\right)+\left(\sum_{l} q l_{l} * W L_{l} * \gamma_{h, l}\right) \\
+\left(\sum_{h} H T_{h} * \alpha_{h, h}\right)+\left(\sum_{g} G T_{g} * \delta_{h, g}\right)+\left(E T * \epsilon_{h}\right)+\left(I T * \zeta_{h}\right)+\left(\sum_{t} \eta_{h, t}\right) \\
F I_{f}=q f_{f} *\left(1-\sum_{g} t f_{g, f}-d p_{f}\right) \\
H T_{h}=H I_{h} *\left(1-\sum_{g} t h_{g, h}\right) \\
H N_{h}=H T_{h} *\left(1-\sum_{h} \alpha_{h, h}-\sum_{t} \theta_{t, h}\right)
\end{gathered}
$$

Utility production by each household, as depicted in figure A.2, is modelled using a top nest (HhTop) where utility is maximised through the consumption of a composite consumer good $(Q Y H C)$ and savings $(Q H S)$ up to the point when the budget constraint $(H N)$ is met as formulated in equation A.19. Consumption and savings are valued at their respective prices, $P Y H C$ and $P H S$. A zero elasticity of substitution is specified by default for this nest $\left(\sigma_{H h T o p}\right)$ to reflect a constant marginal propensity to save. The composite consumer good is the product of a subnest $(H C)$ that reflects substitutability among commodities through an elasticity of substitution $\left(\sigma_{H C}\right)$ of 0.5 . Households are charged an aggregate sales tax for the consumption of the composite consumer good $(t h s)$ : 


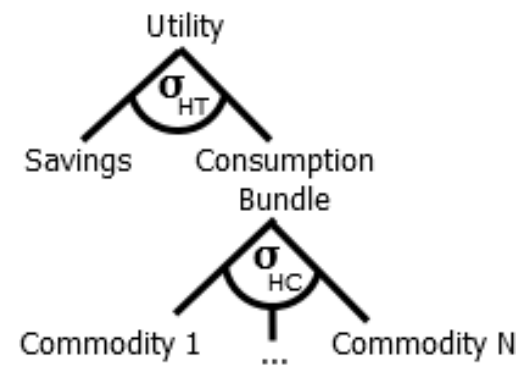

Figure A.2: Representation of households utility production in the CGE model

$$
H N_{h} \geq\left[\left(Q Y H C_{h} * P Y H C_{h}\right) *\left(1+t h s_{h}\right)\right]+\left(P H S_{h} * Q H S_{h}\right)
$$

As reflected in the SAM, there are 6 government divisions $(g)$. The different government divisions generate revenues $(G I)$ partially by selling commodities $(g s)$ at producer's prices $(P Q)$, as formulated in equation A.20. ${ }^{31}$ The volume of sales is fixed at the base year quantity. Some divisions collect taxes and their respective tax rates are inferred from the base-year SAM. Taxes are levied on factor incomes $(t f)$, households' incomes $(t h)$ and enterprises' income $(t e)$. To accommodate to the IMPLAN SAM structure, a portion of the indirect business taxes (IBT) aggregate account has been modelled as a production tax $(t a)$ from different activities (a) in the CGE model. ${ }^{32}$ Hence, the tax is levied on the production by activity $(Q Y A T)$, valued at their respective representative prices $(P Y A T)$. Sales taxes are also collected for commodity purchases from the government (tgs), households (ths), inventory (tns) and investment (tis) accounts. All taxes are distributed to the different government divisions according to a set of shares $(\lambda)$ obtained from the base-year SAM. Duties collected from importing commodities from the rest of the world $(t i)$ are directed to the federal government's non-defense division (' $\left.f n d^{\prime}\right)$. Some divisions also receive a share $(\kappa)$ from other divisions' transferable incomes $(G T)$, a share $(\iota)$ from the investment account's transferable income $(I T)$, and transfers from outside regions $(\mu)$. The transfers coming from the investment account are considered borrowed capital. As shown in equation A.21, government savings $(\xi)$ is assumed to be fixed to the observed figures in the base-year SAM. After considering savings, a portion $(G T)$ of the revenue received by the government divisions is transferred to other institutions. The government divisions' disbursements $(G E)$ consist of the carbon budget $(C B)$ from equation 6, fixed savings $(\xi)$, government consumption of commodities $(Q G)$ valued at purchaser's prices $(P D)$ and subject to an aggregate sales tax $(t g s)$, and the transfer income $(G T)$ to households $(\delta)$, to other government divisions $(\kappa)$, to enterprises $(\nu)$ and to outside regions $(\pi)$ as formulated in A.22. To achieve a complete exhaustion of each government division's budget, government commodity consumption $(Q G)$ is flexible and adjusted from its base-year purchases $(q g)$ equi-proportionately $(\varpi)$ across consumed

\footnotetext{
${ }^{31}$ Not all of the divisions sell commodities.

${ }^{32} \mathrm{ta}$ does not include import duties since these were disaggregated and assigned to a new account in the SAM as explained in $[31]$
} 
commodities as shown in equation A.23.

$$
\begin{aligned}
& G I_{g}=\left(\sum_{c} g s_{g, c} * P Q_{c}\right)+\left(\sum_{f} q f_{f} * W F_{f} * t f_{g, f}\right)+\left(\sum_{h} H I_{h} * t h_{g, h}\right)+\left(E I * t e_{g}\right) \\
& +\lambda_{g} *\left[\left(\sum_{a} Q Y A T_{a} * P Y A T_{a} * t a_{a}\right)+\left(\sum_{h} Q Y H C_{h} * P Y H C_{h} * t h s_{h}\right)\right] \\
& +\lambda_{g} *\left[\left(\sum_{c, g} Q G_{c, g} * P D_{c} * t g s_{g}\right)+\left(\sum_{c} Q N_{c} * P D_{c} * t n s\right)+\left(\sum_{c} Q I_{c} * P D_{c} * t i s\right)\right] \\
& +1^{\prime} f n d^{\prime} *\left(\sum_{t, c} Q X C I_{t, c} * P I M F_{t, c} * t i_{t, c}\right)+\left(\sum_{g} G T_{g} * \kappa_{g, g}\right)+(I T * \iota)+\sum_{t} \mu_{g, t} \\
& G T_{g}=G I_{g}-\xi_{g} \\
& G E_{g}=\left(C B * 1^{\prime} f n d^{\prime}\right)+\xi_{g}+\left[\left(\sum_{c} Q G_{c, g} * P D_{c}\right) *\left(1+t g s_{g}\right)\right]+\left[G T_{g} *\left(\sum_{h} \delta_{h, g}+\sum_{g} \kappa_{g, g} \nu_{g}+\sum_{t} \pi\right)\right] \\
& Q G_{c, g}=q g_{c, g} * \varpi_{g}
\end{aligned}
$$

There is only one representative account for enterprises ('ent'). Enterprises neither sell nor purchase commodities. As mentioned before, enterprises are also endowed with primary factors of production $(q f)$ and land $(q l)$. Again, these endowments are assumed to be fixed to the observed base-year quantities. Instead of distributing net factor incomes $(F I)$ directly to households, enterprises also receive a share $(\beta)$, valued at their respective wages $(W F)$ as formulated in equation A.24. Hence, a good portion of the income $(E I)$ generated by enterprises comes from primary factors. Enterprises also receive a share $(\gamma)$ of the income from the land rented to agricultural activities at their respective rental rates $(W L)$. Some of the government divisions' transferable income $(G T)$ is also devoted to enterprises $(\nu)$. As shown in equation A.25, after accounting for enterprises' income taxes $(t e)$, the rest of the income received by enterprises is transferred $(E T)$ to other institutions. As formulated in equation A.26, enterprises' disbursements $(E E)$ consist of a tax payment $(t e)$ levied on total income $(E I)$, and transfers $(E T)$ to households $(\epsilon)$ and the investment account $(\rho)$. It is important to note that the transfers to households are indirect factor income payments to households. The transfers to the investment account are considered savings and are adjusted proportionately to the income received.

$$
\begin{aligned}
& E I=\left(\sum_{f} F I_{f} * W F_{f} * \beta^{\prime} e n t^{\prime}, f\right)+\left(\sum_{l} q l_{l} * W L_{l} * \gamma^{\prime} e n t^{\prime}, l\right)+\left(\sum_{g} G T_{g} * \nu_{g}\right) \\
& E T=E I *\left(1-\sum_{g} t e_{g}\right) \\
& E E=\left(\sum_{g} t e_{g} * E I\right)+\left[E T *\left(\sum_{h} \epsilon_{h}+\rho\right)\right]
\end{aligned}
$$


There is a representative account for inventories that generates income $(N I)$, partially, from the use of commodities in inventory $(n s)$ at producer's prices $(P Q)$. It receives transfers from outside institutions $(\tau)$ and from net additions to inventory $(\sigma)$, meaning there are more additions to inventory than sales from it. As shown in equation A.27, the only variable in the inventory income formulation is price, the rest being parameters fixed to the observed base-year figures. After accounting for fixed net inventory sales $(v)$, meaning there are more sales from inventory than additions to it, the inventory account's transferable income $(N T)$ to other institutions is formulated as in equation A.28. As shown in equation A.29, inventory's total disbursements $(N E)$ consist of commodities' purchases $(Q N)$ at purchaser's prices $(P D)$ and charged an aggregate sales tax $(t n s)$, inventory's share $(\phi)$ of transferable income $(N T)$ to outside regions, and net inventory sales. To completely exhaust its income, inventory's commodity consumption $(Q N)$ is flexible and adjusted from its base-year purchases ( $q n)$ equi-proportionately $(\chi)$ across consumed commodities as shown in equation A.30.

$$
\begin{gathered}
N I=\left(\sum_{c} n s_{c} * P Q_{c}\right)+\sum_{t} \tau_{t}+\sigma \\
N T=N I-v \\
N E=\left[\left(\sum_{c} Q N_{c} * P D_{c}\right) *(1+t n s)\right]+\left(\sum_{t} \phi_{t} * N T\right)+v \\
Q N_{c}=q n_{c} * \chi
\end{gathered}
$$

There is a representative account for investment and it partially generates income $(I I)$ from the sale of investment commodities $(i s)$ valued at producer's prices $(P Q)$, as formulated in equation A.31. It also receives a share $(d p)$ of the income generated by the capital ('cap') primary factor $(q f)$, valued at its respective price $(W F)$, in the concept of depreciation or capital consumption allowance. Its receipts also consist of the savings generated by households $(Q H S)$, valued at their respective prices $(P H S)$, fixed government savings $(\xi)$, a share $(\rho)$ of enterprises' transferable income $(E T)$, fixed net inventory sales $(v)$ and variable net foreign investment $(N F I)$. Net foreign investment is defined as the difference between foreign spending and receipts. After accounting for fixed net inventory additions $(\sigma)$, the investment account's transferable income $(I T)$ to other institutions is formulated as in equation A.32. Formulated in equation A.33, investment's total disbursements consist of commodity purchases $(Q I)$ valued at purchaser's prices $(P D)$ and charged an aggregate sales tax (tis), net inventory additions $(\sigma)$, investment's income transfers $(I T)$ to households $(\zeta)$, goverment divisions $(\iota)$ and to outside regions $(\psi)$. The transfers to other institutions are considered borrowed capital by the different receiving institutions. To completely exhaust its income, investment's commodity consumption $(Q I)$ is flexible and adjusted from its base-year purchases (qi) equi-proportionately 
$(\omega)$ across consumed commodities as shown in equation A.34.

$$
\begin{gathered}
I I=\left(\sum_{c} i s_{c} * P Q_{c}\right)+\left(d p * q f * W F * 1{ }_{c a p^{\prime}}\right)+\left(\sum_{h} Q H S_{h} * P H S_{h}\right)+\sum_{g} \xi_{g} \\
+(E T * \rho)+v+\sum_{t} N F I_{t} \\
I T=I I-\sigma \\
I E=\left[\left(\sum_{c} Q I_{c} * P D_{c}\right) *(1+t i s)\right]+\left[I T *\left(\sum_{h} \zeta_{h}+\sum_{g} \iota_{g}+\sum_{t} \psi_{t}\right)\right]+\sigma \\
Q I_{c}=q i_{c} * \omega
\end{gathered}
$$

As A.3 shows, all produced and imported commodities enter into the market. Any commodity produced by different domestic sources (activities or institutions) is assumed to be perfectly substitutable and bundled into an aggregate domestic output valued at producer's prices $(P Q){ }^{33}$ Aggregate domestic output is allocated under the assumption that suppliers seek to maximise revenues for any given aggregate output level subject to imperfect transformability, between exports and domestic demand, expressed through a CET function $(C D)$. An elasticity of transformation $\left(\sigma_{C D}\right)$ of -2.5 is used by default for this nest to reflect a high degree of transformation. The share of a commodity that is not exported is supplied to the domestic market, at domestic prices (PDom), and bundled with imports (if imported) into a composite commodity through a CES function $(C T)$. This composite commodity is aggregated under the assumption that demanders seek to minimise costs subject to imperfect substitutability between imports and domestic supply, according to the Armington convention [64]. An elasticity of substitution $\left(\sigma_{C T}\right)$ of 2.5 is used by default for this nest to reflect a high degree of substitution. The composite commodity is demanded by end users (activities and institutions) at purchaser's prices $(P D)$. On the demand side, the model has been designed to find the same market-clearing purchaser's price $(P D)$ across all final consumers for each commodity, equilibrating final demand and composite-commodity supply as shown in equation A.35. In the CGE model, activity and institutional consumption is flexible. On the supply side, the model will find the same market-clearing producer's price $(P Q)$ across all domestic producers for each commodity, equilibrating domestic supply and aggregate-output demand as shown in equation A.36. In the basic CGE model, only production by activities is flexible, institutional production is fixed to the base-year SAM. In the modified IMPLAN SAM, indirect business taxes include sales, production and factor-use taxes. Due to the aggregated nature (and treatment as a production tax in this model) of the indirect business taxes account and to the non-existence of margin accounts (transportation and retail), all commodity transactions in an IMPLAN SAM are expressed in producer's prices. In the model, activities bear the entire burden of the taxes related to commodity production,

\footnotetext{
${ }^{33}$ As opposed to [32] where activity outputs are considered imperfectly substitutable and a CES function is used to aggregate domestic output by activities.
} 
except import duties. Hence, producer's prices already include these taxes. ${ }^{34}$

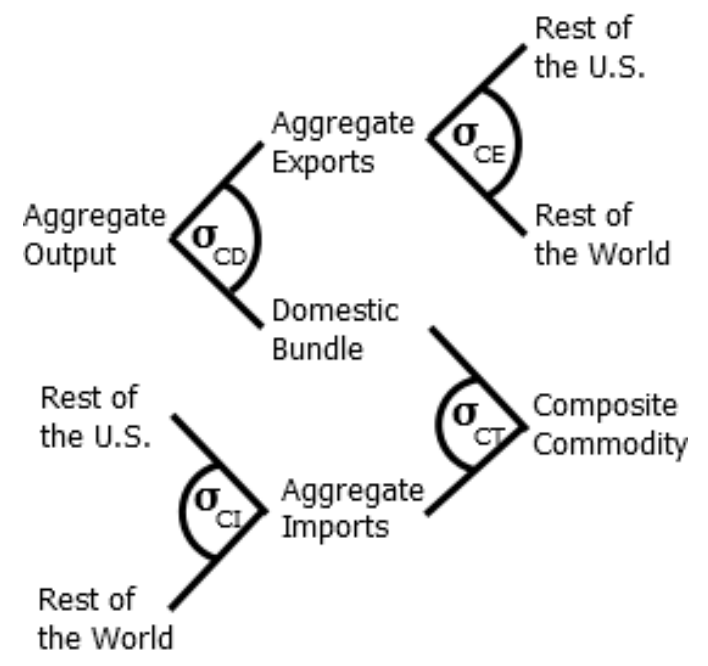

Figure A.3: Representation of commodity markets in the CGE model

$$
\begin{gathered}
Q Y C T_{c} \geq \sum_{h} Q X H C_{h, c}+\sum_{a} Q X A I_{a, c}+\sum_{g} Q G_{g, c}+Q N_{c}+Q I_{c}+X Q A C_{\prime a l g^{\prime}, c}+\sum_{a f} X Q A I_{a f, c} \perp P Y C T_{c} \\
Q Y C D_{c} \leq \sum_{a} Q X J P_{a, c}+\sum_{h} h s_{h, c}+\sum g s_{g, c}+n s_{c}+i s_{c} \perp P Y C D_{c}
\end{gathered}
$$

Since the model is designed to accommodate large and small regional aggregations within the U.S., an exchange rate is not necessary due to the negligible effect that small aggregations would exert on world prices. Hence, traded commodities and institutional transfers are valued at the local currency (U.S. dollars). The model assumes the existence of a representative exporter and importer for commodity-trading purposes. The exporter seeks to maximise revenues by selling aggregate export commodities, to the rest of the U.S. and the rest of the world, and subject to imperfect transformability formulated through a CET function $(C E)$ as depicted in figure A.3. An elasticity of transformation $\left(\sigma_{C E}\right)$ of -2.5 is used by default for this nest to reflect a high degree of transformation. On the other side, the importer seeks to minimise costs by purchasing commodities, from the rest of the U.S. and the rest of the world, and subject to imperfect substitutability expressed as a CES function (ComImp) as depicted in figure A.3. Commodities imported from the rest of the world were subject to import duties. An elasticity of substitution $\left(\sigma_{\text {ComImp }}\right)$ of 2.5 is used by default for this nest to reflect a high degree of substitution. As shown in equation A.37, export demands $(Q E X)$ from outside regions are a function of base-year SAM export quantities (qex) and prices (pex), prices charged by the representative exporter $(P X C E)$ and export demand elasticities $(\Omega)$. PXCE is estimated as a shadow price of the excess supply equation involving export demands $(Q E X)$ and supplies $(Q X C E)$ to each destination as formulated in equation A.38. Import supplies from outside regions $(Q I M)$

\footnotetext{
${ }^{34}$ For any parametrical shock in the CGE model, the vector of market-clearing prices at a solution shows differences between producer's prices $(P Q)$ and purchaser's prices $(P D)$. This difference is due to the effect of import and export prices, respectively.
} 
are a function of base-year SAM import quantities (qim) and prices (pim), free-on-board (FOB) prices charged by the representative foreign exporter at the foreign port (PIMF) and import supply elasticities $(\Gamma)$ as formulated in equation A.39. As formulated in equation A.40, the price paid by the representative importer $(P I M)$ is the FOB price $(P I M F)$ after accounting for import duties $(t i)$. PIMF is estimated as a shadow price of the excess supply equation involving import demands $(Q X C I)$ and supplies $(Q I M)$ from each source as formulated in equation A.41.

$$
\begin{aligned}
Q E X_{c, t}= & q e x_{c, t} *\left(1+\Omega_{c, t}\right) *\left(\frac{P X C E_{c, t}-p e x_{c, t}}{p e x_{c, t}}\right) \\
& Q X C E_{c, t} \geq Q E X_{c, t} \perp P X C E_{c, t} \\
Q I M_{t, c}= & q i m_{t, c} *\left(1+\Gamma_{t, c}\right) *\left(\frac{P I M F_{t, c}-p i m_{t, c}}{p i m_{t, c}}\right) \\
& P I M_{t, c}=P I M F_{t, c} *\left(1+t i_{t, c}\right) \\
& Q I M_{t, c} \geq Q X C I_{t, c} \perp P I M F_{t, c}
\end{aligned}
$$

To completely exhaust the different government divisions' budgets, the closure rule followed in the CGE structure is flexible government commodity consumption $(Q G)$ and fixed savings $(\xi)$. The adjustment factor $(\varpi)$ in equation A.23 helps to achieve this balance and is paired to equation A.42 (following the PATH solver syntax). To achieve a balance for the inventory account, the closure rule followed in the basic CGE structure is flexible inventory commodity consumption $(Q N)$ and fixed net inventory deletions $(v)$. Again, the adjustment factor $(\chi)$ in equation A.30 helps to achieve this balance and is paired to equation A.43. The same closure rule followed for the two previous institutions is applied to the investment account - investment commodity consumption $(Q I)$ is flexible. However, net foreign income $(N F I)$ is also flexible in this case, as will be explained later. The adjustment factor $(\omega)$ in equation A.34 helps to achieve this balance and is paired to equation A.44.

$$
\begin{gathered}
G I_{g}=G E_{g} \\
N I=N E \\
I I=I E
\end{gathered}
$$

As previously mentioned, the model is designed to accommodate large and small regional aggregations within the U.S. Hence, an exchange rate variable is not necessary due to the negligible effect that small aggregations would exert on world prices. Thus, the closure variable for the trade accounts is net foreign investment $(N F I)$. As shown in equation A.45, the left-hand-side variables reflect receipts by the trade accounts consisting of commodity import quantities $(Q I M)$ valued at their respective import FOB prices $(P I M F)$, and the different transfers to outside regions by factors $(\Lambda * F I)$, households $(\theta * H T)$, government divisions $(\pi * G T)$, investment $(\psi * I T)$ and inventory $(\phi * N T)$. The right-hand-side variables and parameters represent transfers from outside regions such as commodity export quantities $(Q E X)$ valued at their respective export prices $(P E X)$, foreign transfers to households $(\eta)$, government divisions $(\mu)$, inventory $(\tau)$ 
and investment account or net foreign investment $(N F I)$.

$$
\begin{aligned}
\left(\sum_{c} Q I M_{c, t} * P I M F_{c, t}\right) & +\left(\sum_{f} \Lambda_{t, f} * F I_{f}\right)+\left(\sum_{h} \theta_{t, h} * H T_{h}\right)+\left(\sum_{g} \pi_{t, g} * G T_{g}\right)+\left(\psi_{t} * I T\right) \\
& +\left(\phi_{t} * N T\right)=\left(\sum_{c} Q E X_{c, t} * P E X_{c, t}\right)+\sum_{h} \eta_{h, t}+\sum_{g} \mu_{g, t}+\tau_{t}+N F I_{t} .
\end{aligned}
$$

\section{Appendix B: Regional Afforested Set-Asides Carbon Sequestration Rates}

Since Birdsey [7] reported the carbon storage estimates for different forest types and this study only considers the two major timber categories (softwood and hardwood), only one forest type from each major category was used for each region as shown in table B.1. Birdsey [7] estimated rates for eight different regions in the U.S. for softwoods and hardwoods (with the exception of the Rocky Mountains, Mid-Atlantic and Pacific Coast).

To distribute the regional $\mathrm{CO}_{2}$ uptake rates shown in table B.1 into the MLRAs included in the regional aggregation, different weighted averages were estimated. By assigning the regional uptake rates (tseq) to every state in the regional aggregation (reg) and using the acreage of the land-use types (tacres) in each state as weights $(w t)$, a single uptake rate was estimated for each MLRA, land-use type and timber category $(s e q)$ :

$$
\begin{gathered}
w t_{\text {reg }, l, \text { use }, \text { wood }}=\frac{\text { tacres }_{\text {reg }, l, u s e, w o o d}}{\sum_{\text {reg }} \text { tacres }_{\text {reg }, l, \text { use }, \text { wood }}}, \\
\text { seq }_{l, \text { use }, w o o d}=\sum_{\text {reg }} t_{s e q_{\text {reg }, l, \text { use }, w o o d} * w t_{\text {reg }, l, \text { use }, \text { wood }} .}
\end{gathered}
$$

As an example, if reg included Alabama and Florida only, the Southern Coastal Plain MLRA is present in both states and had cropland acreage figures of 807,231 and 221,049 , respectively. The estimated cropland-tosoftwood $\mathrm{CO}_{2}$ uptake rates in the Southern Coastal Plain MLRA in Alabama and Florida are 0.162 and 0.175 acres/MT/year, respectively. Hence, the regional weighted average $\mathrm{CO}_{2}$ uptake rate for that specific MLRA is $0.165 \mathrm{acres} / \mathrm{MT} /$ year or seq $^{\prime} 234^{\prime}{ }^{\prime}$ 'crop $^{\prime},{ }^{\prime}$ soft $^{\prime}=(807,231 / 1,028,280)(0.162)+(221,049 / 1,028,280)(0.175)$. 


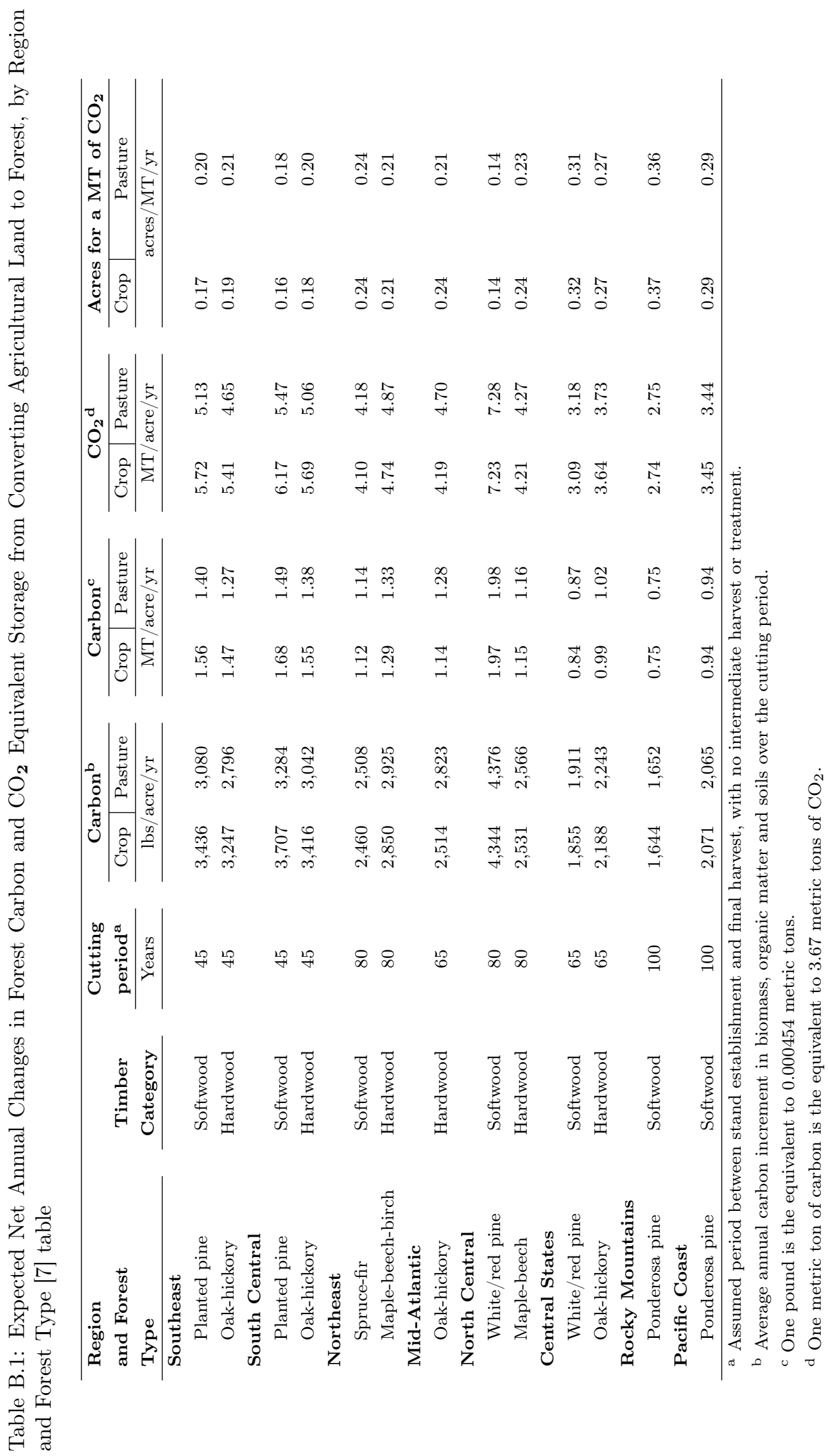




\section{Appendix C: Regional Afforested Set-Asides Establishment Costs}

The most cited study reporting regional afforestation costs for cropland and pastureland is Moulton and Richards [52]. In this study, the activities included in the costs were land preparation, seedlings, planting, and post-planting treatment and care required to ensure establishment. ${ }^{35}$ These regional treatment costs were estimated for irrigated and non-irrigated cropland and pastureland. Since the difference among the costs was not considerable, a simple average was taken of both irrigated and non-irrigated lands. However, Moulton and Richards [52] estimated afforestation costs of cropland and pastureland without differentiating between the two major timber categories, as shown in the second and third columns of table C.1a. ${ }^{36}$

Bair and Alig [53] estimated afforestation costs for each land-use type and timber category, as shown in table C.1b. According to them, afforestation costs for hardwood in any region in the U.S. were $25 \%$ higher than for softwood. The problem with Bair and Alig [53] for present needs is that cost estimates were provided only for three major regions in the U.S.

Table C.1: Afforestation Costs From Previous Literature

(a) Afforestation Costs in Moulton and Richards (1990)

\begin{tabular}{lccccccc}
\hline \multirow{2}{*}{ Region } & & Crop & Past & & \multicolumn{2}{c}{ Crop } & Past \\
\cline { 7 - 8 } \cline { 6 - 7 } \cline { 5 - 7 } Southeast & & \multicolumn{2}{c}{$\$ /$ acre } & & \multicolumn{2}{c}{ Differential } \\
\cline { 6 - 7 } Lake States & & 105.50 & 67.00 & & 1.00 & 1.00 \\
Corn Belt & & 136.00 & 186.00 & & 2.29 & 2.78 \\
North Plains & & 97.00 & 102.00 & & 1.63 & 1.52 \\
Appalachian & & 62.00 & 89.00 & & 1.04 & 1.33 \\
Northeast & & 150.00 & 196.00 & & 2.52 & 2.93 \\
Delta States & & 69.50 & 77.00 & & 1.17 & 1.15 \\
South Plains & & 57.00 & 63.00 & & 0.96 & 0.94 \\
Mountain & & 70.00 & 109.00 & & 1.18 & 1.63 \\
Pacific & & 180.00 & 215.00 & & 3.03 & 3.21 \\
\hline
\end{tabular}

(b) Afforestation Costs in Bair and Alig (2006)

\begin{tabular}{llccc}
\hline $\begin{array}{l}\text { Region and } \\
\text { Timber Categories }\end{array}$ & & Crop & Past \\
\cline { 1 - 1 } Southeast & & 2002 & $\$ /$ acre \\
$\quad$ Softwood & & \\
$\quad$ Hardwood & & 81.16 & 103.01 \\
South Central & & & \\
$\quad$ Softwood & & 73.29 & 80.62 \\
$\quad$ Hardwood & & 91.61 & 100.77 \\
Corn Belt & & & \\
$\quad$ Softwood & & 114.36 & 157.07 \\
$\quad$ Hardwood & & 142.95 & 196.34 \\
\hline
\end{tabular}

Both studies were used to estimate a more complete set of costs for every region in Moulton and Richards [52] and every major timber category in Bair and Alig [53]. As shown in the fourth and fifth columns of table C.1a, cost differentials were estimated among the different regional aggregations considered in Moulton and Richards [52]. The Southeast region was taken as a reference since $90 \%$ of total forest acreage was planted with softwood trees, as reported in Moulton and Richards [52]. Hence, by multiplying the cost differentials of every region in Moulton and Richards [52] by the cost estimates from Bair and Alig [53] for softwood and hardwood in the Southeast, and adjusting for inflation, a more complete set of costs was obtained as shown in the first five columns of table C.2. Since the estimates in Bair and Alig [53] are in 2002 dollars, to adjust

\footnotetext{
${ }^{35}$ According to Richards and Stokes [9], Moulton and Richards [52] included provisions for a $15 \%$ failure rate increasing the cost estimates.

${ }^{36}$ For each region, Moulton and Richards [52] estimated the treatment costs using historical planting patterns of a given mixture of tree species.
} 
for inflation, a factor of 1.04 was estimated by considering the percent change between the Producers Price Index (PPI) in 2002 to 2008.

To assign the regional annualised cost estimates in table C.2 to every MLRA, land-use type and timber category in the regional aggregation, the same procedure followed previously for carbon uptake rates was followed for costs. Hence, by replacing tseq and seq for the cost estimate at the state level (tcost) and at the regional level (cost) in equation B.2, an afforestation cost was obtained for each MLRA, land-use type and timber category. 


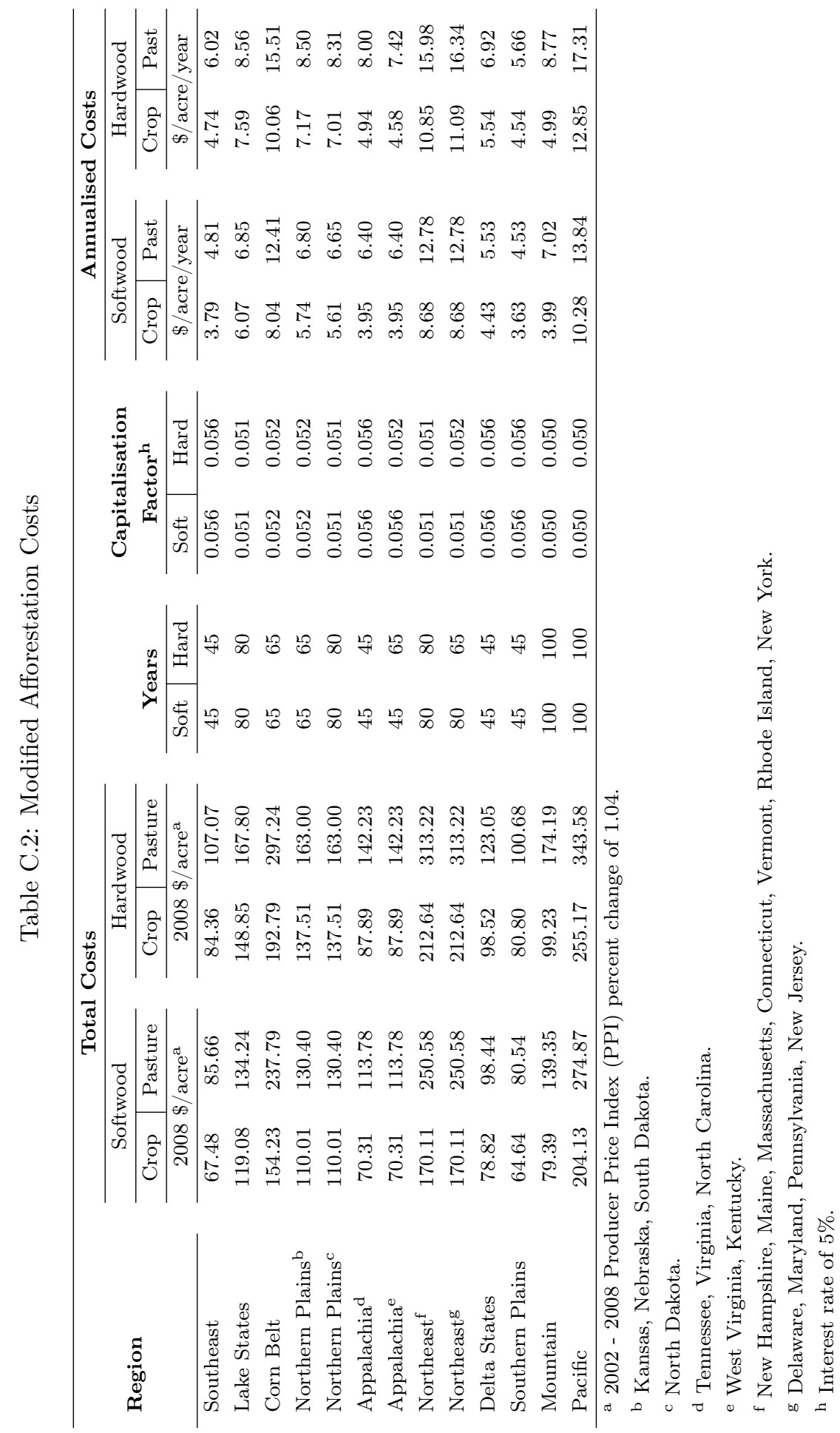




\section{Appendix D: Regional Afforested Set-Asides Land Rent Costs}

The rent figures estimated for cropland and pastureland in Monge and Bryant [48] for every MLRA were included in the model in the following manner:

$$
\begin{aligned}
P X L A_{l,,^{\prime} \text { crld }} & =\frac{\sum_{a c r} \text { trent }_{l, a c r}}{\sum_{a c r} \text { acres }_{l, a c r}}, \\
P X L A_{l,{ }^{\prime} \text { psld }^{\prime}} & =\frac{\sum_{a p s} \text { trent }_{l, a p s}}{\sum_{\text {aps }} \text { acres }_{l, a p s}}, \\
\text { rent }_{l, \text { use }} & =P X L A_{l, \text { use }},
\end{aligned}
$$

where acr and aps are the sets representing the activities demanding cropland and pastureland, respectively; 'crld' and 'psld' are the two elements of the set use; and trent are the total rents paid from every industry using land to every MLRA and estimated in Monge and Bryant [48]. 